\title{
Why the South Pacific Convergence Zone is diagonal
}

\author{
2 Karin van der Wiel - Adrian J. \\ Matthews - Manoj M. Joshi • David P. \\ 4 Stevens
}

6 Received: date / Accepted: date

\begin{abstract}
During austral summer, the majority of precipitation over the Pacific Ocean is concentrated in the South Pacific Convergence Zone (SPCZ). The surface boundary conditions required to support the diagonally (northwest-southeast) oriented SPCZ are determined through a series of experiments with an atmospheric general circulation model. Continental configuration and orography do not have a significant influence on SPCZ orientation and strength. The key necessary boundary condition is the zonally asymmetric component of the sea surface temperature (SST) distribution. This leads to a strong subtropical anticyclone over the southeast Pacific that, on its western flank, transports warm moist air from the equator into the SPCZ region. This moisture then intensifies (diagonal) bands of convection that are initiated by regions of ascent and reduced static stability ahead of
\end{abstract}

K. van der Wiel

Centre for Ocean and Atmospheric Sciences, University of East Anglia, Norwich, UK School of Environmental Sciences, University of East Anglia, Norwich, UK

Tel.: +44 (0)1603 592556

E-mail: k.van-der-wiel@uea.ac.uk

\section{A. J. Matthews}

Centre for Ocean and Atmospheric Sciences, University of East Anglia, Norwich, UK

School of Environmental Sciences, University of East Anglia, Norwich, UK

School of Mathematics, University of East Anglia, Norwich, UK

M. M. Joshi

Centre for Ocean and Atmospheric Sciences, University of East Anglia, Norwich, UK

School of Environmental Sciences, University of East Anglia, Norwich, UK

Climatic Research Unit, University of East Anglia, Norwich, United Kingdom

D. P. Stevens

Centre for Ocean and Atmospheric Sciences, University of East Anglia, Norwich, UK School of Mathematics, University of East Anglia, Norwich, UK 
the cyclonic vorticity in Rossby waves that are refracted toward the westerly duct over the equatorial Pacific. The climatological SPCZ is comprised of the superposition of these diagonal bands of convection. When the zonally asymmetric SST component is reduced or removed, the subtropical anticyclone and its associated moisture source is weakened. Despite the presence of Rossby waves, significant moist convection is no longer triggered; the SPCZ disappears. The diagonal SPCZ is robust to large changes (up to $\pm 6^{\circ} \mathrm{C}$ ) in absolute SST (i.e. where the SST asymmetry is preserved). Extreme cooling (change $<-6^{\circ} \mathrm{C}$ ) results in a weaker and more zonal SPCZ, due to decreasing atmospheric temperature, moisture content and convective available potential energy.

Keywords SPCZ · SST · IGCM4 · asymmetry · Rossby waves · moisture transport

\section{Introduction}

The South Pacific Convergence Zone (SPCZ) is a major feature in the distribution of precipitation over the southern hemisphere tropical Pacific Ocean during austral summer (Fig. 1a). The SPCZ is oriented diagonally, stretching northwest-southeast from New Guinea to the central, subtropical Pacific Ocean (Vincent, 1994). In the northern hemisphere a comparable diagonal band of precipitation is not found; instead there is a zonal band of precipitation at about $8^{\circ} \mathrm{N}$, the Intertropical Convergence Zone (ITCZ).

General Circulation Models (GCMs) have difficulty simulating a diagonal SPCZ. The collection of state-of-the-art models in the Coupled Model Intercomparison Project Phase 5 (CMIP5) generally model a SPCZ that is too zonal and where the subtropical portion is displaced (Brown et al, 2013; Niznik et al, 2015). There are many atmospheric processes and feedbacks that have been linked to the SPCZ; these need to be well represented in the GCMs in order for them to simulate a realistic SPCZ. Low-level inflow by easterly trade winds (Lintner and Neelin, 2008; Niznik and Lintner, 2013) and orographically forced subsidence (Takahashi and Battisti, 2007b) set the location of the eastern margin of the SPCZ. Tropical-extra tropical interactions through Rossby waves have been associated with the SPCZ since it was first observed (e.g. Streten, 1973; Trenberth, 1976). More recently, Widlansky et al (2011) linked wave energy accumulation in the jet exit to the SPCZ. Matthews 
(2012) and Van der Wiel et al (2015) develop a framework in which it is shown that convection in the SPCZ is forced by the equatorward propagation and the diagonal orientation of Rossby wave trains. This framework depends on a background climatological state to facilitate all aspects of the mechanism. How robust the SPCZ mechanism is to changes in the background state and what aspects of the background state cause changes to the SPCZ are still open questions.

The aim of this study is to determine how boundary conditions influence the background state, atmospheric dynamical and thermodynamical processes and what their effect is on the diagonal SPCZ, using an atmospheric GCM. Any climatological differences between the northern and southern hemisphere (ITCZ vs. SPCZ) must be forced by differences in boundary conditions, i.e. differences in continental configuration (land-sea contrasts), orography and sea surface temperatures (SSTs). In an atmospheric GCM, as used in this study, SSTs are an externally specified boundary condition. Of course, in a coupled model and in the actual climate system, SSTs are set by the combined effects of seafloor bathymetry, continental configuration, ocean circulation and atmosphere-ocean interactions.

The SST pattern over the Pacific has strong zonal and meridional gradients. Changes in the distribution of tropical SSTs, e.g. due to El Niño-Southern Oscillation (ENSO), have been related to changes in the position of the SPCZ (e.g. Folland et al, 2002; Juillet-Leclerc et al, 2006; Vincent et al, 2011; Haffke and Magnusdottir, 2013). During El Niño events, when warm water from the equatorial warm pool moves eastward, decreasing the zonal SST difference, the SPCZ moves eastward and equatorward. During La Niña events, when zonal SST asymmetries in the equatorial Pacific are magnified, the SPCZ moves westward and poleward. For strong El Niño events (1982/1983, 1991/1992, $1997 / 1998)$ the SPCZ disappears in favour of a zonal precipitation band over the equator (Vincent et al, 2011). These 'zonal SPCZ' events are predicted to occur more frequently in future warmer climates (Cai et al, 2012; Borlace et al, 2014).

The direct influence of orography on the SPCZ is not as clear. Takahashi and Battisti (2007a,b) and Kitoh (2002) tested this by means of coupled model experiments. Though the SPCZ proved to be sensitive to adding/removing orography, it was not possible to separate the direct effect of the Andes on atmospheric processes from the indirect effect of the Andes through altered SSTs on atmospheric processes. The role of southern Pacific land-sea contrasts 
was tested in experiments by Kiladis et al (1989), though again Pacific SSTs were altered as well. It was concluded that the presence of Australia alters precipitation rates in the western part of the SPCZ and that South America has no influence. The experiments in this study have been designed to test the direct effects of all boundary conditions separately. Indirect effects of orography and land-sea contrasts, through altered SSTs, are not be considered.

The remainder of the paper is organized as follows: Sect. 2 describes the model and discusses its ability to simulate the diagonal SPCZ. In Sect. 3 the different experiments are described. Experimental results are shown in Sect. 4 and a final discussion of the findings is given in Sect. 5 .

\section{Model description and verification}

The Intermediate Global Circulation Model version 4 (IGCM4, Joshi et al, 2015 ) is used to perform experiments testing the influence of different boundary conditions on SPCZ position and strength. It is an intermediatecomplexity atmospheric model, i.e. it has simpler physical parameterizations compared to, for example, the atmospheric component of GCMs used in CMIP5. However, the quality of the simulated precipitation in IGCM4 is within the range of models in the CMIP5 ensemble (AMIP experiment Joshi et al, 2015).

Dry convection is modelled by means of an immediate adjustment to neutrality in a single time step (Forster et al, 2000). Moist convective processes are based on the scheme described by Betts (1986), either in a shallow nonprecipitation type or a deep, precipitation convection type. Estimates of cloud cover are done by means of the scheme of Slingo (1987). Radiation is based on a modified Morcrette scheme (Zhong and Haigh, 1995). Monthly SSTs are prescribed and were computed using data from the NOAA Optimum Interpolation V2 (Reynolds et al, 2002, mean over 1982-2009). Land surface temperatures are computed self consistently (Forster et al, 2000).

Here the IGCM4 version with a spectral truncation of T42 and 20 layers in the vertical is used. The model is integrated for 17 years in each experiment, the first year of which is removed for spin-up. Therefore 16 years of data remain, with 15 November to April seasons in which the SPCZ is most strongly developed.

A quantitative comparison of SPCZ orientation is obtained following the approach of Brown et al $(2011,2012,2013)$. In the domain where the SPCZ 
is well defined $\left(155^{\circ} \mathrm{E}\right.$ to $140^{\circ} \mathrm{W}, 0^{\circ}$ to $\left.30^{\circ} \mathrm{S}\right)$ the latitude of maximum precipitation is found for each band of longitude. A linear least-squares fit to the resulting points gives an objective estimation of the latitudinal position of the SPCZ axis and its slope (in ${ }^{\circ} \mathrm{N} /{ }^{\circ} \mathrm{E}$ ). We do not use a threshold of minimum precipitation for the selected points, as the focus here is mostly on investigating the diagonal orientation of the SPCZ, independent from its strength. Therefore, the SPCZ strength is defined separately as the mean precipitation rate in a parallelogram along the fitted axis. The width of the parallelogram is $10^{\circ}$ of latitude (see black boxes in Figs. 1a, 1b).

First, we describe the characteristics of the SPCZ in a control experiment. The November to April time mean precipitation for observations and in the IGCM4 control integration is shown in Figs. 1a, 1b. The observations are on the based precipitation product from the CMAP project (Xie and Arkin, 1997), from 1979 to 2008 on a $2.5^{\circ} \times 2.5^{\circ}$ grid. In the climate of the IGCM4 control integration, the position of the $4 \mathrm{~mm} \mathrm{~d}^{-1}$ contour, a proxy for the SPCZ margin, is simulated well at the eastern boundary of the SPCZ, although the simulated SPCZ western boundary is located too far east. The slope of the SPCZ axis is $-0.37^{\circ} \mathrm{N} /{ }^{\circ} \mathrm{E}$ in the control integration, which is slightly more slanted than the observed SPCZ $\left(-0.27^{\circ} \mathrm{N} /{ }^{\circ} \mathrm{E}\right)$. The precipitation rate is underestimated in the more tropical part of the SPCZ, resulting in a mean SPCZ strength of $7.50 \mathrm{~mm} \mathrm{~d}^{-1}$ instead of $9.25 \mathrm{~mm} \mathrm{~d}^{-1}$ in CMAP. The computed SPCZ strength is plotted against SPCZ slope in Fig. 1c. For a quality comparison of the modelled SPCZ in IGCM4 the data from 23 CMIP5 models ${ }^{1}$ are also included. The quality of the SPCZ based on strength and slope in the IGCM4 control integration is within the range of CMIP5 atmosphere only ('AMIP') experiments. The coupled version of these models ('historical' experiment) simulate an SPCZ that is too zonal (Brown et al, 2013), from the models taken into account here only MIROC5 and CMCC-CM simulate a diagonal SPCZ in coupled mode (slope $<-0.1^{\circ} \mathrm{N} /{ }^{\circ} \mathrm{E}$ ).

A second diagonally oriented precipitation band can be found over South American continent and the southern Atlantic ocean. The South Atlantic Convergence Zone (SACZ) is formed by a comparable dynamical mechanism

1 Models included: ACCESS1.0, ACCESS1.3, BCC-CSM1.1, BCC-CSM1.1-m, BNUESM, CanCM4, CCSM4, CESM1(CAM5), CMCC-CM, CNRM-CM5, CSIRO-Mk3.6.0, FGOALS-g2, GFDL-CM3, GISS-E2-R, HadGEM2-AO, IPSL-CM5A-LR, IPSL-CM5A-MR, IPSL-CM5B-LR, MIROC5, MPI-ESM-LR, MPI-ESM-MR, MRI-CGCM3, NorESM1-M. Details of the CMIP5 experimental setup and model configurations, model physics and references can be found at http://cmip-pcmdi.llnl.gov/cmip5/. November to April time means are based on simulated data from 1979-2005. 
as the SPCZ (Van der Wiel et al, 2015). In the control integration (Fig. 1b) the SACZ slope is similar to the observed slope. Simulated precipitation values are higher in the continental part of the SACZ and lower in the oceanic part. Precipitation in the ITCZ over the Pacific is slightly weaker than observed.

\section{Experimental Setup}

Four different sets of experiments were designed to separately test the influence of SST asymmetries, absolute SST values, orography and land-sea contrasts on diagonal SPCZ orientation and strength. The model setup for each of these experiments is described below (see also Table 1).

\subsection{SST asymmetry}

This set of model integrations varies the strength of the zonally asymmetric part of the SST field, i.e. the zonal SST gradients. First, the zonal mean SST field $\left(S S T_{z m}\right)$ is calculated. For a given latitude, the zonal mean SST is the mean SST over all the ocean grid points along that particular latitude. The asymmetric part of the SST field $\left(S S T_{\text {asym }}\right)$ is the difference between the total $\left(S S T_{c t r l}\right)$ and zonal mean fields:

$$
S S T_{\text {asym }}=S S T_{\text {ctrl }}-S S T_{z m}
$$

These calculations are carried out globally, for each month in the seasonally varying SST climatology. The model linearly interpolates the monthly SST fields onto the relevant model Julian day. Finally, the strength of the zonally asymmetric SST field used in the experiments is determined by the dimensionless parameter $\alpha$ :

$$
S S T_{e x p}=S S T_{z m}+\alpha \times S S T_{a s y m} .
$$

Integrations were carried out for $\alpha$ in the range $-0.5 \leq \alpha \leq 2$. Here, $\alpha=0$ corresponds to the zonal mean SST field, $\alpha=1$ corresponds to the control integration, $0<\alpha<1$ and $\alpha>1$ corresponds to weaker and stronger SST gradients, respectively, and $\alpha<0$ corresponds to reversed SST gradients. 
3.2 Absolute SST

This is a series of integrations with globally increasing or decreasing SST values, set by the parameter $\beta\left({ }^{\circ} \mathrm{C}\right)$ :

$$
S S T_{\exp }=S S T_{c t r l}+\beta .
$$

A range of IGCM4 integrations has been completed for $\beta$ in the range $-12^{\circ} \mathrm{C}$ $\leq \beta \leq+8^{\circ} \mathrm{C}$. Note that by definition $\beta=0^{\circ} \mathrm{C}$ is the control integration.

\subsection{No orography}

This experiment was run with all mountains removed; all land surface is flat.

\subsection{No land}

Some of the land surface is changed into ocean. Instead of calculating surface temperatures interactively, monthly mean surface temperatures are prescribed, by linearly interpolating east to west from (former) coast to coast. Orography is preserved as in the control integration, i.e. mountains on the removed continents are now 'aqua mountains'. Two separate integrations have been done: (i) removing Australia, New Zealand and the maritime continent and (ii) removing South America.

\section{Experimental results}

\subsection{SST asymmetry}

\subsubsection{Large-scale impact on the $S P C Z$}

Zonal and meridional SST gradients have been linked to the diagonally oriented SPCZ in many studies (e.g. Widlansky et al, 2011, 2013; Nieto Ferreira and Chao, 2013). Hence we conduct ten integrations with either increased zonal SST asymmetry $(\alpha>1)$ or decreased asymmetry $(\alpha<1)$. The SST fields forcing the model are shown in Fig. 2. Note that $\alpha=1$ is the control integration and $\alpha=0$ has zonally symmetric SST forcing. For $\alpha=2$ any departures from the zonal mean SST values are doubled, the west Pacific warm 
pool is warmer, the east Pacific cold tongue is colder. For each longitudinal band the zonal mean SST value remains constant.

For increasing asymmetry the SPCZ remains in position; the slope is $-0.26^{\circ} \mathrm{N} /{ }^{\circ} \mathrm{E}$ and the strength increases up to $12.00 \mathrm{~mm} \mathrm{~d}^{-1}$ for $\alpha=2$. The precipitation rate increases along the entire length of the SPCZ, consequently the southeastern tip extends about $10^{\circ}$ further eastward. In the northern hemisphere the ITCZ is weaker compared to the control integration. In Fig. 3a the mean precipitation mid-SPCZ $\left(15^{\circ}-25^{\circ} \mathrm{S}\right)$ is shown for all integrations in the SST asymmetry experiment. For $\alpha \geq 1$ the strength increases steadily and the longitude at which maximum precipitation is found does not shift.

Zonally symmetric SST forcing $(\alpha=0)$ does not support any form of a diagonally oriented SPCZ. Precipitation over the Pacific ocean is focused in one broad band situated over the equator (Fig. 2d). The strongest precipitation rate is just north of the equator. Three model integrations were performed spanning the range from the control integration to the zonally symmetric SST integration. For $\alpha=0.75$ both SPCZ strength and orientation are very close to the SPCZ in the control integration. For $\alpha=0.5$ (Fig. 2f) the SPCZ strength is much weaker. Though there is a weak sign of diagonally oriented precipitation, the SPCZ identification criteria from Brown et al (2011, 2012, 2013) fail to identify it, precipitation just south of the equator is stronger and therefore selected as the SPCZ axis. Finally, for $\alpha=0.25$ (not shown) there is no evidence of a diagonally oriented precipitation pattern. The critical value required for a diagonal SPCZ lies therefore somewhere around $\alpha=0.5$. The shift of the SPCZ at $\alpha=0.5$ is also visible in Fig. 3a.

For the integration with $\alpha=-0.5$ the zonal SST gradients are reversed, the warmest water is now over the equatorial east Pacific. The strongest precipitation rates are found over the warmest waters; there is no diagonal SPCZ.

Fig. $3 \mathrm{~b}$ shows the zonal mean precipitation rate over the Pacific ocean $\left(150^{\circ} \mathrm{E}-90^{\circ} \mathrm{W}\right)$. In the control integration, the maximum precipitation rate is in the ITCZ at $5^{\circ} \mathrm{N}$. In the southern hemisphere there is no clear maximum, instead there is a steady decrease in precipitation rate towards a minimum at $30^{\circ} \mathrm{S}$. Between $12^{\circ}$ and $25^{\circ} \mathrm{S}$ the SPCZ reduces the decrease of the precipitation rate with latitude. The integrations with a weakened zonal SST asymmetry (low $\alpha$ ) show an accentuation of this pattern. The SPCZ bump decreases in strength, the near-equatorial maxima increase in strength. For integrations with an increasing SST asymmetry (high $\alpha$ ), the near-equatorial maxima are 
weaker and the SPCZ bump increases in strength, such that by $\alpha=1.5$ it becomes a distinct local maximum. For $\alpha=2$ the overall maximum is no longer in the northern hemisphere ITCZ, instead it is at about $15^{\circ} \mathrm{S}$ in the SPCZ. In these experiments, the precipitation rate in the SPCZ is inversely related to the precipitation rate in the ITCZ: increasing SST asymmetry result in stronger SPCZ and weaker ITCZ precipitation (Figure 2).

\subsubsection{Impact on transient wave-convection SPCZ framework}

As the zonal asymmetry $(\alpha)$ is decreased, the diagonal SPCZ disappears. However, the SPCZ is not a direct convective response to the underlying SST distributions. As discussed in Sect. 1, the climatological SPCZ arises from the superposition of many individual synoptic events, where extratropical Rossby waves are refracted and take on a diagonal orientation, triggering convection in a diagonal band ahead of the cyclonic vorticity axis. In this section, we investigate which of the links in this mechanism are sensitive to the SST changes and ultimately cause the SPCZ to disappear as the SST zonal asymmetry is reduced.

Adapting the methodology of Van der Wiel et al (2015), composite life cycles of the transient wave - convection SPCZ framework were constructed for the control experiment (Fig. 4, left) and the zonally symmetric SST experiment (Fig. 4, right). Composites are defined to find whether dynamical changes, thermodynamical changes or a mix of the two cause the diagonal SPCZ to disappear when the model is forced with zonal SSTs.

These composites are based on time series of $200-\mathrm{hPa}$ vorticity anomalies (mean values in a box southwest of the SPCZ, $20^{\circ}-30^{\circ} \mathrm{S}, 180^{\circ}-170^{\circ} \mathrm{W}$, southwest blue box in Fig. 4e). Events are then selected based on two criteria: (i) the vorticity anomaly is more negative than -1 standard deviation, and (ii) the vorticity anomaly is a relative minimum compared to five days before and after the event. Based on the above criteria 157 events were selected in the control integration and 158 events in the zonally symmetric SST integration. Composites were computed by taking the mean of a field over all event days.

In the control integration $(\alpha=1)$, four days before the event a wave train originating in the subtropical jet is refracted towards the SPCZ area (Figs. 4a, 4c). At the day of the event (Fig. 4e), ahead of a cyclonic vorticity anomaly precipitation is formed within the SPCZ. The wave train then weakens and deflects to the southeast (Figs. 4g, 4i). This is in agreement with the physical 
mechanism and the negative feedback between Rossby wave propagation and precipitation discussed in Matthews (2012) and Van der Wiel et al (2015).

In the zonally symmetric SST integration $(\alpha=0)$ a comparable wave train propagates over the SPCZ region (Figs. 4b, 4d). However, here it does not trigger significant convection and precipitation over the SPCZ region (Fig. 4f). The negative feedback does not act and wave propagation continues towards the equator (Figs. 4h, 4j). The Rossby wave forcing up to the event is similar between the two integrations. Therefore, there must be a difference in the thermodynamics that causes the SPCZ to disappear when the model is forced by zonal SSTs.

Vertical profiles of temperature and humidity have been analysed in the location where the dynamical forcing triggers precipitation in the composites in the control integration (northeast light blue box in Fig. $4 \mathrm{e}, 15^{\circ}-25^{\circ} \mathrm{S}, 170^{\circ}$ $160^{\circ} \mathrm{W}$ ). Both temperature (Fig. 5a) and specific humidity (Fig. 5b) are lower in the zonally symmetric SST integration; the resulting decrease of relative humidity (Fig. 5c) is substantial. The convection scheme (Betts, 1986) is sensitive to this change; computed deep convection is shallower and produces less precipitation.

The difference in atmospheric humidity can be explained by differences in atmospheric moisture supply. In the control integration, the lower tropospheric flow over the Southern Hemisphere subtropical Pacific is dominated by a strong subtropical anticyclone (wind vectors in Fig. 6a). On the large scale, the lower tropospheric humidity is characterised by the moist tropics and drier subtropics (shading in Fig. 6a). The subtropical anticyclone advects dry air equatorwards in the eastern Pacific. On its western flank moist air is advected polewards into the SPCZ region. This moisture then converges along the SPCZ axis (Fig. 6c), supplying the moisture for the convection ahead of the transient waves in Fig. 4e.

In the zonally symmetric SST integration, the lower tropospheric circulation response over the South Pacific is also approximately zonally symmetric. There is no distinct subtropical anticyclone over the eastern Pacific, and the subtropical flow is eastward and equatorward (trade winds) at all longitudes across the Pacific (wind vectors in Fig. 6b). Hence, there is no poleward moisture advection in the southwest Pacific and no moisture convergence to feed an SPCZ (Fig. 6d). Therefore, even though the dynamical forcing from transient waves over the southwest Pacific is still present (Fig. 4f), 
the moisture supply needed for this to trigger the deep convective events that comprise the SPCZ is absent.

\subsection{Absolute SST}

Ten integrations have been performed in the absolute SST experiment, with SST values changing from $\beta=-12^{\circ} \mathrm{C}$ to $\beta=+8^{\circ} \mathrm{C}$. For a selection of these integrations the new SST fields forcing for the model and the resulting precipitation patterns are shown in Fig. 7 . Within this $20^{\circ} \mathrm{C}$ range of temperatures, the SPCZ is a constant feature over the southern Pacific. For $-4^{\circ} \mathrm{C} \leq \beta \leq+8^{\circ} \mathrm{C}$ its diagonal orientation is stable, with the slope varying between $-0.27^{\circ} \mathrm{N} /{ }^{\circ} \mathrm{E}$ and $-0.37^{\circ} \mathrm{N} /{ }^{\circ} \mathrm{E}$. For the integrations with $\beta$ decreasing beyond $-6^{\circ} \mathrm{C}$, the slope decreases from $-0.36^{\circ} \mathrm{N} /{ }^{\circ} \mathrm{E}$ to $-0.08^{\circ} \mathrm{N} /{ }^{\circ} \mathrm{E}$ $\left(\beta=-12^{\circ} \mathrm{C}\right)$ and the SPCZ loses most of its diagonal orientation. Overall, the SPCZ precipitation rate increases with warmer SSTs, from $5.05 \mathrm{~mm} \mathrm{~d}^{-1}$ $\left(\beta=-12^{\circ} \mathrm{C}\right)$ to $9.39 \mathrm{~mm} \mathrm{~d}^{-1}\left(\beta=+8^{\circ} \mathrm{C}\right)$. Precipitation over ocean surfaces outside the SPCZ changes in a similar way. The ITCZ, the oceanic portion of the SACZ and precipitation over the maritime continent all decrease or disappear with cooling SSTs.

In the IGCM4 the convective precipitation rate is determined by the atmospheric stability and moisture content. Convective available potential energy (CAPE) provides an estimate of the likelihood and the intensity of atmospheric convection (Riemann-Campe et al, 2009). Based on model output, CAPE is computed from vertical profiles of temperature and surface humidity. Fig. 8 shows mean vertical temperature profiles along the SPCZ for $\beta=-8^{\circ} \mathrm{C}$, $\beta=0{ }^{\circ} \mathrm{C}$ and $\beta=+8^{\circ} \mathrm{C}$. In the control integration CAPE is $1827 \mathrm{~J} \mathrm{~kg}^{-1}$. In the warmer experiment both temperature and specific humidity have increased throughout the troposphere. The idealised lifted parcel shows convection is deeper and, as shown before, produces more precipitation (Fig. 7l). The CAPE for this profile is $3047 \mathrm{~J} \mathrm{~kg}^{-1}$. In the colder experiment temperature and specific humidity decrease and the tropopause height is lower. CAPE decreases to $996 \mathrm{~J} \mathrm{~kg}^{-1}$, convection is shallower and precipitation is weaker. Other integrations in this experiment show similar trends of temperature, moisture content and CAPE.

The convective inhibition (CIN), a measure for the stability of the surface layer, remains approximately constant in all experiments at about $31 \mathrm{~J} \mathrm{~kg}^{-1}$. 
Any changes to modelled convection must therefore have been caused by changes to atmospheric temperature, moisture content and CAPE.

In general, the model atmospheric response to globally warming SSTs is an increase in atmospheric temperature and moisture content. As a result CAPE increases and modelled convection is deeper and produces more precipitation. The mechanism is similar to that of the 'wet gets wetter' (Held and Soden, 2006) and projections of future warmer climates in CMIP5 (Widlansky et al, 2013). Lower-tropospheric relative humidity remains constant. The mean precipitation change along the SPCZ is approximately $0.24 \mathrm{~mm} \mathrm{~d}^{-1}{ }^{\circ} \mathrm{C}^{-1}$.

For negative $\beta$, CAPE values decrease all over the South Pacific (Fig. 9). The highest values of CAPE are found in two zonal bands just off the equator, separated by a minimum over the equator. Additionally, in the southern hemisphere high CAPE values are found further poleward in a slightly diagonal band. The diagonal SPCZ does not follow this band of high CAPE, it is more diagonally oriented (i.e. it has larger slope in ${ }^{\circ} \mathrm{N} /{ }^{\circ} \mathrm{E}$ ). The SPCZ slope is still set by northwest-southeast oriented vorticity centres in Rossby wave trains. Ahead of the cyclonic anomalies, static stability is reduced and, when conditions are suitable, deep convection is triggered parallel to the axis of the vorticity centre. (Matthews, 2012; Van der Wiel et al, 2015).

For extremely cold integrations $\left(\beta<-6^{\circ} \mathrm{C}\right)$ the SPCZ becomes gradually weaker and loses its diagonal orientation. The colder and drier atmosphere makes conditions less favourable for deep convection. At the southeastern end of the SPCZ, within the $4 \mathrm{~mm} \mathrm{~d}^{-1}$ margin $\left(25-35^{\circ} \mathrm{S}, 120-130^{\circ} \mathrm{W}\right.$, light blue box in Fig. 9a), CAPE decreases from $1085 \mathrm{~J} \mathrm{~kg}^{-1}$ in the control integration to 789 $\mathrm{J} \mathrm{kg}^{-1}$ for $\beta=-4^{\circ} \mathrm{C}, 485 \mathrm{~J} \mathrm{~kg}^{-1}$ for $\beta=-8^{\circ} \mathrm{C}$ and $342 \mathrm{~J} \mathrm{~kg}^{-1}$ for $\beta=-12^{\circ} \mathrm{C}$. In the extremely cold integrations, the SPCZ starts to align with the highest CAPE values over the South Pacific, as the conditions at the southeastern end of the control SPCZ are no longer suitable for deep convection. In the other integrations, CAPE values are sufficiently high everywhere equatorward of $30^{\circ} \mathrm{S}$ to support deep convective precipitation. Consequently, the SPCZ is found wherever the dynamic forcing from the equatorward propagating Rossby waves is.

\subsection{No orography}

In the no-orography experiment, the SPCZ axis remains in approximately the same position as in the control integration and its diagonal orientation is 
almost unchanged $\left(-0.36^{\circ} \mathrm{N} /{ }^{\circ} \mathrm{E}\right.$; Fig. 10). The mean precipitation rate along the axis is $7.27 \mathrm{~mm} \mathrm{~d}^{-1}$, only slightly lower than in the control experiment. The southeastern limit of the SPCZ extends about $10^{\circ}$ further eastward. These minimal changes indicate that the direct influence of orography on the SPCZ through changes to the atmosphere is small.

This result agrees with comparable model experiments by Takahashi and Battisti (2007a,b) and Widlansky et al (2011). The Takahashi and Battisti (2007a,b) experiment was designed by adding complexity to an aqua planet rather than decreasing complexity from the full model as has been done here. Their results indicate that the South American continent and the Andes mountain range have a very small influence on the Pacific precipitation pattern. However, if atmosphere-ocean feedbacks are included in this experiment (through an interactive mixed layer or a coupled ocean model) southern Pacific precipitation does change (Kitoh, 2002; Takahashi and Battisti, 2007a,b).

Outside the SPCZ region, precipitation is now mostly focused within the zonal ITCZ. The SACZ disappears, in favour of a zonal ITCZ from the Amazon extending into the Atlantic. Furthermore, the directly orographically forced precipitation west of the Andes and over New Guinea disappears in the experiment. The detailed mechanism for the changes in the SACZ region is beyond the scope of this study.

\subsection{No land}

Over the removed continents in the no-land experiments the surface forcing has changed. In the no-land Australia integration, the temperatures over Australia decrease southwards from $29^{\circ} \mathrm{C}$ to $20^{\circ} \mathrm{C}$ and the interpolated temperature contours are oriented west-to-east (Fig. 11a). In the no-land South America integration, the interpolated SST contours are oriented in a northwestsoutheast direction, due to the upwelling of cold water in the eastern Pacific compared to relative warm water at the same latitudes in the western Atlantic (Fig. 11b). These SST patterns have not been designed to be a 'realistic' representation of the SSTs in the case that the continents were actually not there. Instead, the experiments have been designed to test the influence of continental heating from land surfaces on the SPCZ, whilst keeping any other forcing equal (including SSTs over the oceans). 
Without continental heating over Australia, New Zealand, and the maritime continent, the SPCZ remains in place (Figs. 11c, 11e). The new slope is $-0.34^{\circ} \mathrm{N} /{ }^{\circ} \mathrm{E}$, slightly less diagonal than in the control integration. Within the SPCZ margin the precipitation rate has somewhat decreased, giving a slightly weaker SPCZ strength $\left(7.03 \mathrm{~mm} \mathrm{~d}^{-1}\right)$. Precipitation over Australia and the maritime continent has increased. This is likely to be caused by the increased near-surface water vapour pressure when land surface is changed to sea surface in the model and the fact that these relatively humid surfaces are not at sea level.

Similarly the influence of South American continental heating on the SPCZ seems to be small, the change in SPCZ orientation and strength is minimal (Figs. 11d, 11f). The slope of the SPCZ in the experiment is $-0.35^{\circ} \mathrm{N} /{ }^{\circ} \mathrm{E}$, its strength $7.83 \mathrm{~mm} \mathrm{~d}^{-1}$. As was found in the no-Australia integration, the largest precipitation changes appear over the removed continent of South America.

To test the influence of the aqua mountains, an additional integration was performed in which all continents and all orography were removed (not shown). The results were not significantly different from the no-land integrations presented here. Kiladis et al (1989) performed equivalent experiments in a GCM. Despite having prescribed a different SST forcing over the removed continents and changing SST patterns in open ocean, their results match the current no-land South America experiment. The location of the simulated SPCZ in their model is biased towards Australia, consequently removing continental heating there has a more significant effect.

\section{Conclusions}

Experiments have been conducted using the IGCM4 to test the influence of atmospheric boundary conditions on the SPCZ. Experiments included zonal SST asymmetries, absolute SST values, global orography and continental configuration (the presence of Australia and South America). The quality of the simulated SPCZ in the IGCM4 control run is within the range of 23 CMIP5 AMIP experiments. SPCZ slope and strength from all experiments are plotted in Fig. 12, together with the control integration, observational data and 23 CMIP5 coupled model historical experiments. The figure shows the SPCZ is a very robust climatological feature. Removing orography or removing the Australian or South American continents has very little influence; the 
experimental SPCZ is almost identical to the SPCZ in the control integration in these cases.

Zonal SST asymmetries impact both SPCZ strength and slope. Stronger asymmetries lead to a stronger SPCZ $\left(+4.5 \mathrm{~mm} \mathrm{~d}^{-1}\right.$ for $\left.\alpha=2\right)$. La Niña events are comparable to these experiments and the experimental results agree with the observed stronger SPCZ during such events (e.g. Folland et al, 2002; JuilletLeclerc et al, 2006). Decreasing SST asymmetries towards zonally symmetric values impacts the SPCZ slope. The modelled diagonal SPCZ collapses when the asymmetry is half as strong as observed values $(\alpha=0.5)$, instead there is a wide band of precipitation over the equator. Such a collapse of the SPCZ to a zonal band of precipitation has been observed during extreme El Niño events (e.g. Vincent et al, 2011; Cai et al, 2012). The upper-tropospheric dynamical forcing does not change in these integrations; it is atmospheric thermodynamics that makes the difference. The subtropical high, west of the Andes provides moisture to the SPCZ (Fig. 13a). With decreasing zonal SST asymmetry this moisture transport slows down and despite dynamical forcing, convection is not triggered (Fig. 13b). Similar lower-tropospheric moisture convergence anomalies have been observed during extreme El Niño events (Vincent et al, 2011).

The absolute SST experiments show that SST values impact the SPCZ strength. For increasing SSTs the SPCZ holds its diagonal orientation whilst the precipitation rate increases by $+1.9 \mathrm{~mm} \mathrm{~d}^{-1}$ for the $\beta=$ $+8^{\circ} \mathrm{C}$ integration. Vertical profiles of temperature and humidity indicate that computed convection reaches higher and produces more precipitation. Decreasing SSTs has the opposite effect. For extremely cold cases the SPCZ loses its diagonal orientation; values of CAPE over the South Pacific are too low for deep convection and strongest precipitation is found over the area with highest CAPE, parallel to the SST contours. These extremely cold integrations are in agreement with model experiments of the Last Glacial Maximum (21 ky $\mathrm{BP}, \mathrm{CO}_{2} 180$ ppm, northern ice sheet) in which the SPCZ is shifted northwards (Saint-Lu et al, 2015).

From the ensemble of IGCM4 experiments it can therefore be concluded that there are prerequisite conditions that need to be met to create a diagonal SPCZ. Asymmetries in the SST pattern are shown to be vital. Though not considered in the current experiments, air-sea interactions and ocean basin boundaries are, ultimately, responsible for these asymmetries (Seager and Murtugudde, 1997). The high pressure area that consequently forms over the 
subtropical eastern Pacific transports warm, moist air from the equator to the SPCZ region. Then, when the dynamical forcing is right, deep convection produces precipitation over the SPCZ (Fig. 13a).

Coral isotope based studies of the SPCZ in past climates so far focus mainly on the eigtheenth-century onwards (Bagnato et al, 2005; Juillet-Leclerc et al, 2006). These studies give valuable information of climatic variations in the SPCZ and provide additional information to verify output from GCMs for different climate basic states. However, to make reliable statements on SST distributions and the SPCZ further back in time, a more dense network of isotope cores is needed. If such data were available, an interesting question following the current study would be, whether the onset of the SPCZ coincides with the onset of zonal SST gradients about 1-2 Myr ago (McClymont and Rosell-Mele, 2005; Brierley and Fedorov, 2010).

Twenty-first-century projections of SPCZ precipitation are uncertain in the CMIP5 ensemble, however SST projections are consistent and show an equatorial warming and reduced zonal and meridional gradients (Brown et al, 2013; Widlansky et al, 2013). Based on the physical mechanisms presented here and the CMIP5 SST projections, the future of the SPCZ depends on the relative strength of two competing effects. Increasing absolute SST values force stronger SPCZ precipitation, while decreased zonal SST gradients force weaker SPCZ precipitation; this uneasy balance agrees with model experiments by Widlansky et al (2013).

\footnotetext{
Acknowledgements The CMAP and NOAA IO V2 data were provided by the NOAA/OAR/ESRL PSD, Boulder, Colorado, USA, from their web site at http://www.cdc.noaa.gov/. We acknowledge the World Climate Research Programme's Working Group on Coupled Modelling, which is responsible for CMIP, and we thank the climate modelling groups for producing and making available their model output. The CMIP5 data was downladed from http://cmip-pcmdi.llnl.gov/cmip5/. The research presented in this article was carried out on the High Performance Computing Cluster supported by the Research Computing Service at the University of East Anglia. The authors would like to thank two anonymous reviewers for comments which helped to improve the manuscript.
}

\section{References}

Bagnato S, Linsley BK, Howe SS, Wellington GM, Salinger J (2005) Coral oxygen isotope records of interdecadal climate variations in the South Pacific 
Convergence Zone region. Geochemistry Geophysics Geosystems 6:Q06,001, DOI 10.1029/2004GC000879

Betts AK (1986) A new convective adjustment scheme. Part I: Observational and theoretical basis. Quarterly Journal of the Royal Meteorological Society 112:677 - 691, DOI 10.1002/qj.49711247307

Borlace S, Santoso A, Cai W, Collins M (2014) Extreme swings of the South Pacific Convergence Zone and the different types of El Niño events. Geophysical Research Letters 41:4695-4703, DOI 10.1002/2014GL060551

Brierley CM, Fedorov AV (2010) Relative importance of meridional and zonal sea surface temperature gradients for the onset of the ice ages and Pliocene-Pleistocene climate evolution. Paleoceanography 25:PA2214, DOI 10.1029/2009PA001809

Brown JR, Power SB, Delage FP, Colman RA, Moise AF, Murphy BF (2011) Evaluation of the South Pacific Convergence Zone in IPCC AR4 climate model simulations of the twentieth century. Journal of Climate 24:1565 1582, DOI 10.1175/2010JCLI3942.1

Brown JR, Moise AF, Delage FP (2012) Changes in the South Pacific Convergence Zone in IPCC AR4 future climate projections. Climate Dynamics 39:1 - 19, DOI 10.1007/s00382-011-1192-0

Brown JR, Moise AF, Colman RA (2013) The South Pacific Convergence Zone in CMIP5 simulations of historical and future climate. Climate Dynamics 41:2179 - 2197, DOI 10.1007/s00382-012-1591-x

Cai W, Lengaigne M, Borlace S, Collins M, Cowan T, McPhaden MJ, Timmermann A, Power S, Brown J, Menkes C, Ngari A, Vincent EM, Widlansky MJ (2012) More extreme swings of the South Pacific Convergence Zone due to greenhouse warming. Nature 488:365 - 370, DOI 10.1038/nature11358

Folland CK, Renwick JA, Salinger MJ, Mullan AB (2002) Relative influences of the Interdecadal Pacific Oscillation and ENSO on the South Pacific Convergence Zone. Geophysical Research Letters 29:1643, DOI 10.1029/2001GL014201

Forster PMdF, Blackburn M, Glover R, Shine KP (2000) An examination of climate sensitivity for idealised climate change experiments in an intermediate general circulation model. Climate Dynamics 16:833 - 849, DOI $10.1007 / \mathrm{s} 003820000083$ 
Haffke C, Magnusdottir G (2013) The South Pacific Convergence Zone in three decades of satellite images. Journal of Geophysical Research 118:1 11, DOI 10.1002/jgrd.50838

Held IM, Soden BJ (2006) Robust responses of the hydrological cycle to global warming. Journal of Climate 19:5686 - 5699, DOI 10.1175/JCLI3990.1

Joshi MM, Stringer M, Van der Wiel K, O'Callaghan A, Fueglistaler S (2015) IGCM4: a fast, parallel and flexible intermediate climate model. Geoscientific Model Development In press

Juillet-Leclerc A, Thiria S, Naveau P, Delcroix T, Le Bec N, Blamart D, Correge T (2006) SPCZ migration and ENSO events during the 20th century as revealed by climate proxies from a Fiji coral. Geophysical Research Letters 33, DOI 10.1029/2006GL025950

Kiladis GN, von Storch H, van Loon H (1989) Origin of the South Pacific Convergence Zone. Journal of Climate 2:1185 - 1195, DOI 10.1175/15200442(1989)002<1185:OOTSPC $>2.0 . \mathrm{CO} ; 2$

Kitoh A (2002) Effects of large-scale mountains on surface climate. A coupled ocean-atmosphere general circulation model study. Journal of the Meteorological Society of Japan 80:1165 - 1181, DOI 10.2151/jmsj.80.1165

Lintner BR, Neelin JD (2008) Eastern margin variability of the South Pacific Convergence Zone. Geophysical Research Letters 35:L16,701, DOI 10.1029/2008GL034298

Matthews AJ (2012) A multiscale framework for the origin and variability of the South Pacific Convergence Zone. Quarterly Journal of the Royal Meteorological Society 138:1165 - 1178, DOI 10.1002/qj.1870

McClymont EL, Rosell-Mele A (2005) Links between the onset of modern Walker circulation and the mid-Pleistocene climate transition. Geology 33:389 - 392, DOI 10.1130/G21292.1

Nieto Ferreira R, Chao WC (2013) Aqua-planet simulations of the formation of the South Atlantic convergence zone. International Journal of Climatology 33:615 - 628, DOI 10.1002/joc.3457

Niznik MJ, Lintner BR (2013) Circulation, moisture and precipitation relationships along the South Pacific Convergence Zone in reanalyses and CMIP5 models. Journal of Climate 26:10,174 - 10,192, DOI 10.1175/JCLID-13-00263.1

Niznik MJ, Lintner BR, Matthews AJ, Widlansky MJ (2015) The role of tropical-extratropical interaction and synoptic variability in maintaining 
the South Pacific Convergence Zone in CMIP5 models. Journal of Climate Accepted for publication

Reynolds RW, Rayner NA, Smith TM, Stokes DC, Wang W (2002) An improved in situ and satellite SST analysis for climate. Journal of Climate 15:1609 - 1625, DOI 10.1175/1520-0442(2002)015<1609:AIISAS > 2.0.CO;2

Riemann-Campe K, Fraedrich K, Lunkeit F (2009) Global climatology of convective available potential energy (CAPE) and convective inhibition (CIN) in ERA-40 reanalysis. Atmospheric Research 93:534 - 545, DOI 10.1016/j.atmosres.2008.09.037

Saint-Lu M, Braconnet P, Leloup J, Lengaigne M, Marti O (2015) Changes in the ENSO/SPCZ relationship from past to future climates. Earth and Planetary Science Letters 412:18 - 24, DOI 10.1016/j.epsl.2014.12.033

Seager R, Murtugudde R (1997) Ocean dynamics, thermocline adjustment, and regulation of tropical SST. Journal of Climate 10:521-534, DOI 10.1175/1520-0442(1997)010<0521:ODTAAR >2.0.CO;2

Slingo JM (1987) The development and verification of a cloud prediction scheme for the ECMWF model. Quarterly Journal of the Royal Meteorological Society 113:899 - 927, DOI 10.1002/qj.49711347710

Streten NA (1973) Some characteristics of satellite-observed bands of persistent cloudiness over the Southern Hemisphere. Monthly Weather Review 101:486 - 495, DOI 10.1175/1520-0493(1973)101<0486:SCOSBO > 2.3.CO;2

Takahashi K, Battisti DS (2007a) Processes controlling the mean tropical Pacific precipitation pattern. Part I: The Andes and the Eastern Pacific ITCZ. Journal of Climate 20:3434 - 3451, DOI 10.1175/JCLI4198.1

Takahashi K, Battisti DS (2007b) Processes controlling the mean tropical Pacific precipitation pattern. Part II: the SPCZ and the southeast Pacific dry zone. Journal of Climate 20:5696 - 5706, DOI 10.1175/2007JCLI1656.1

Trenberth KE (1976) Spatial and temporal variations of the Southern Oscillation. Quarterly Journal of the Royal Meteorological Society 102:639 - 653, DOI 10.1002/qj.49710243310

Van der Wiel K, Matthews AJ, Stevens DP, Joshi MM (2015) A dynamical framework for the origin of the diagonal South Pacific and South Atlantic Convergence Zones. Quarterly Journal of the Royal Meteorological Society DOI 10.1002/qj.2508, published online

Vincent DG (1994) The South Pacific Convergence Zone (SPCZ): a review. Monthly Weather Review 122:1949 - 1970, DOI 10.1175/1520- 
0493(1994)122<1949:TSPCZA>2.0.CO;2

Vincent EM, Lengaigne M, Menkes CE, Jourdain NC, Marchesiello P, Madec G (2011) Interannual variability of the South Pacific Convergence Zone and implications for tropical cyclone genesis. Climate Dynamics 36:1881 - 1896, DOI 10.1007/s00382-009-0716-3

Widlansky MJ, Webster PJ, Hoyos CD (2011) On the location and orientation of the South Pacific Convergence Zone. Climate Dynamics 36:561 - 578, DOI 10.1007/s00382-010-0871-6

Widlansky MJ, Timmermann A, Stein K, McGregor S, Schneider N, England MH, Lengaigne M, Cai W (2013) Changes in South Pacific rainfall bands in a warming climate. Nature Climate Change 3:417 - 423, DOI 10.1038/nclimate1726

Xie P, Arkin PA (1997) Global precipitation: a 17-year monthly analysis based on gauge observations, satellite estimates, and numerical model outputs. Bulletin of the American Meteorological Society 78:2539 - 2558, DOI 10.1175/1520-0477(1997)078<2539:GPAYMA > 2.0.CO;2

Zhong WY, Haigh JD (1995) Improved broad-band emissivity parameterization for water vapor cooling calculations. Journal of Atmospheric Sciences 52:124 - 138, DOI 10.1175/1520-0469(1995)052<0124:IBEPFW>2.0.CO;2 
Table 1 Overview of IGCM4 experiments conducted.

\begin{tabular}{ll}
\hline Experiment & Description \\
\hline Control & Standard IGCM4 \\
SST asymmetry & Zonal mean SSTs + SST asymmetry $(\alpha)$ \\
Absolute SST & Standard SST patterns + absolute change $(\beta)$ \\
No orography & Flat earth \\
No land & - No Australia, New Zealand and maritime continent \\
& - No South America \\
\hline
\end{tabular}


(a)

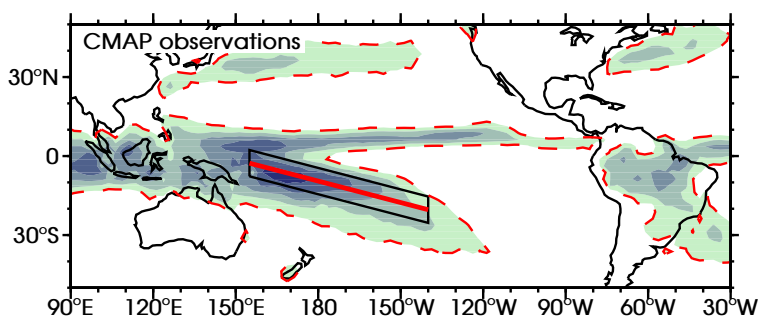

(b)

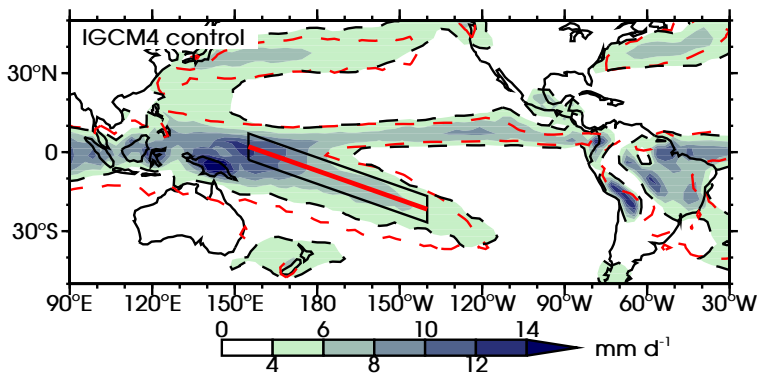

(c)

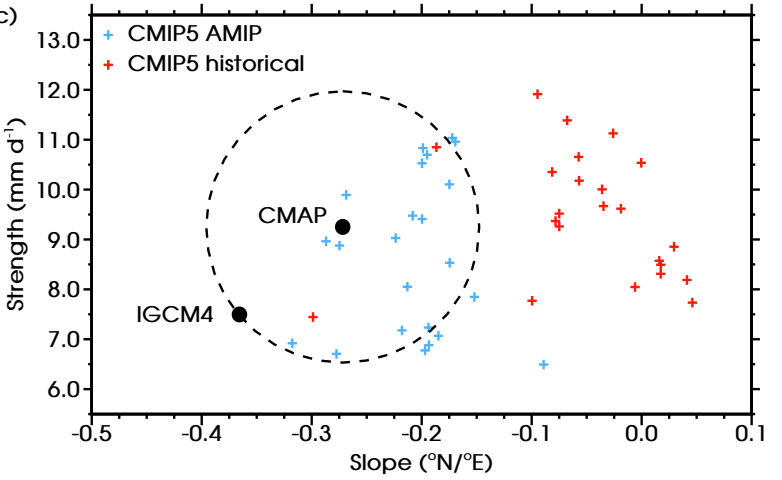

Fig. 1 Time mean precipitation rate (November to April) in (a) CMAP and (b) IGCM4 control integration (shaded colours, $\mathrm{mm} \mathrm{d}^{-1}$ ). The thick diagonal red lines in $(\mathrm{a}, \mathrm{b})$ show the computed SPCZ axis locations, the red dashed lines in $(\mathrm{a}, \mathrm{b})$ show the $4 \mathrm{~mm} \mathrm{~d}^{-1}$ contour in CMAP, the black dashed line in (b) shows this contour in the IGCM4 control integration, black parallelograms in $(\mathrm{a}, \mathrm{b})$ are the area for the computation of the SPCZ strength (see text). (c) SPCZ strength $\left(\mathrm{mm} \mathrm{d}^{-1}\right)$ plotted against $\mathrm{SPCZ}$ slope $\left({ }^{\circ} \mathrm{N} /{ }^{\circ} \mathrm{E}\right)$. Black dots are the CMAP observations and the IGCM4 control integration, additionally CMIP5 AMIP experiments (blue crosses) and CMIP5 historical experiments (red crosses) are shown. The dashed line in (c) is the circle centred on the CMAP observations that passes through the point of the IGCM4 control integration. 
(a) $30^{\circ}$

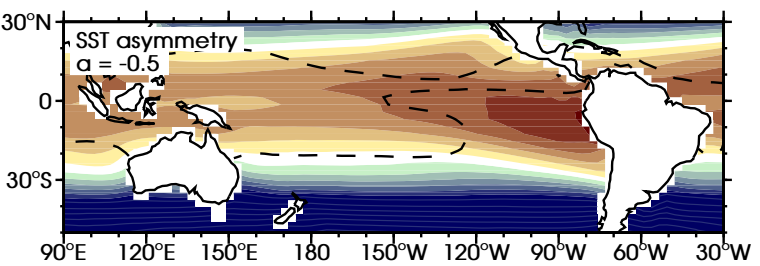

(c) 30

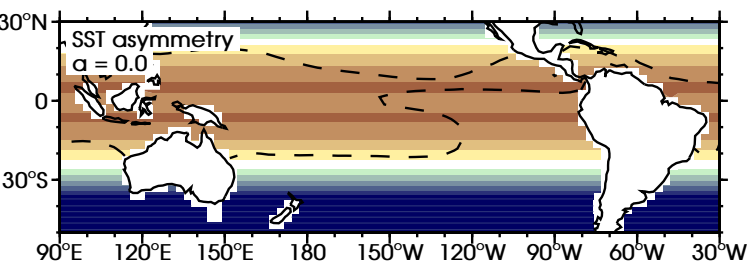

(e) $30^{\circ}$

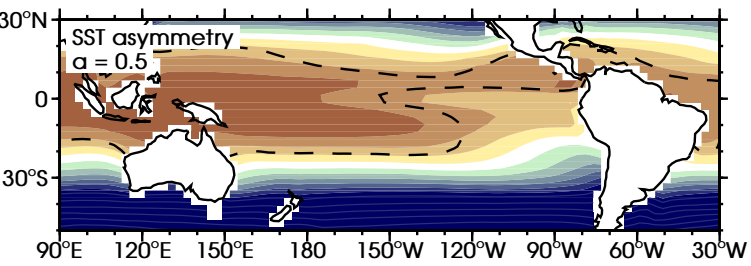

(g) $30^{\circ}$

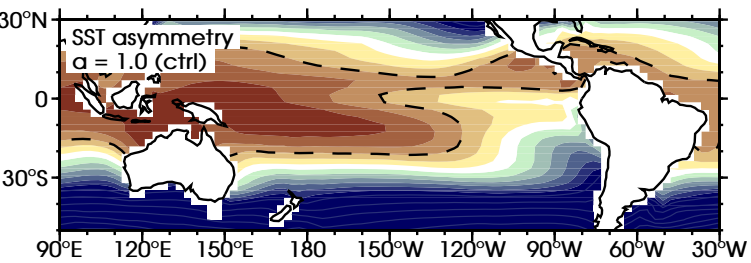

(i)

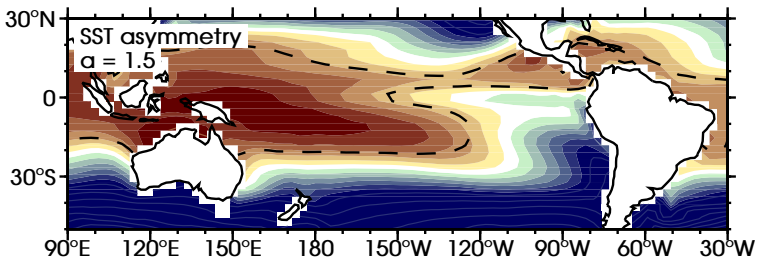

(k) 30

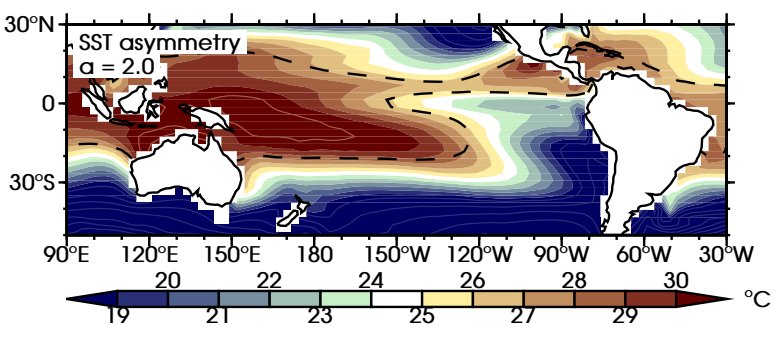

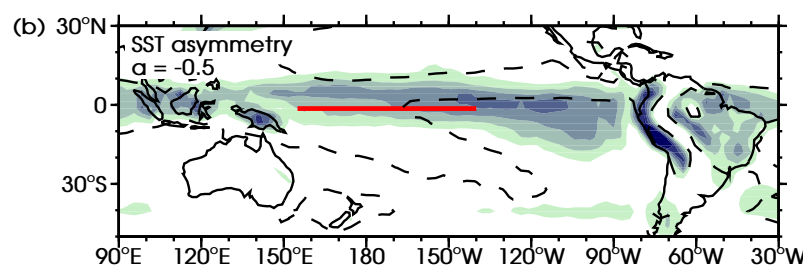

(d) 30

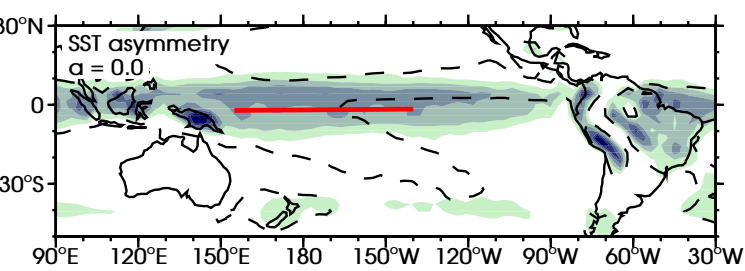

(f)

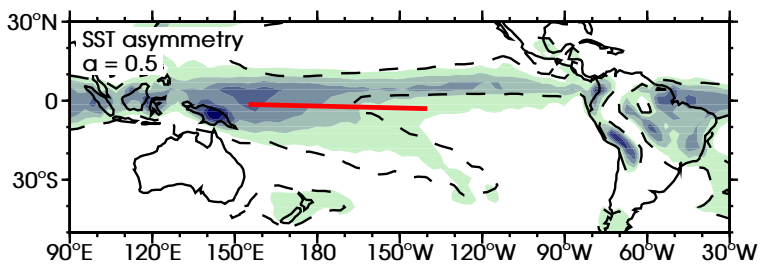

(h) $30^{\circ} \mathrm{N}$

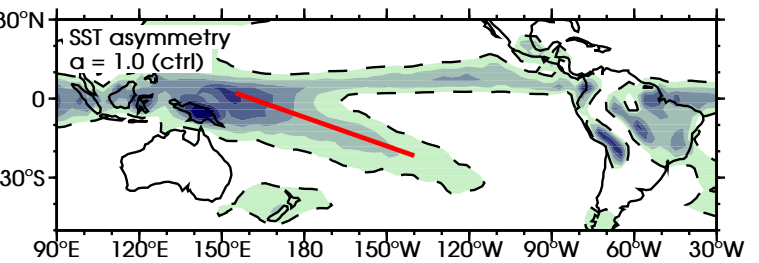

(j) $30 \times 1$ (n)

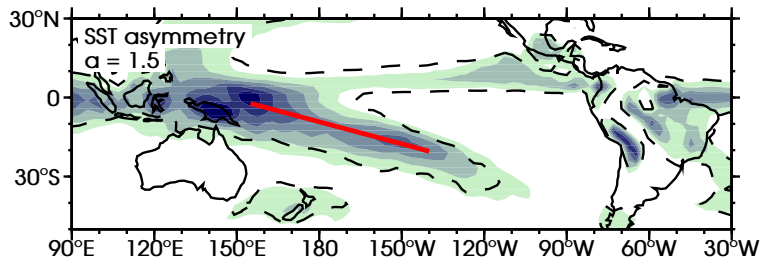

(l)

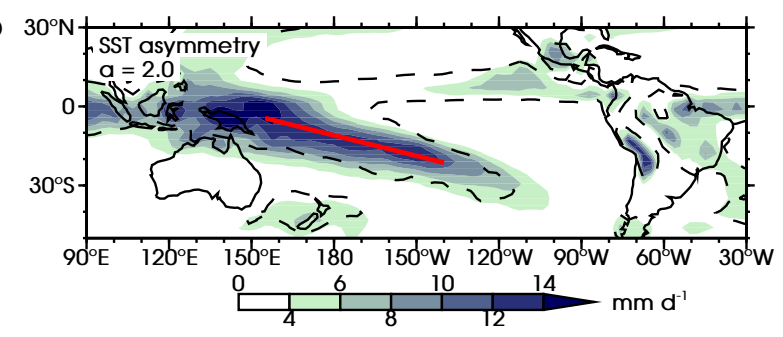

Fig. 2 SST asymmetry experiments. (Left) Time mean SST forcing (November to April, shaded colours, ${ }^{\circ} \mathrm{C}$ ), black dashed line shows the $27^{\circ} \mathrm{C}$ contour of the IGCM4 control integration (as in g), brown line contours show SST contours for $31^{\circ} \mathrm{C}$ and warmer $\left(+1^{\circ} \mathrm{C}\right.$ contour interval), blue line contours show SST contours for $17^{\circ} \mathrm{C}$ and colder $\left(-2^{\circ} \mathrm{C}\right.$ contour interval). (Right) The corresponding time mean precipitation rate (shaded colours, $\mathrm{mm}$ $\mathrm{d}^{-1}$ ), the thick diagonal red line shows the computed SPCZ axis location, the black dashed line shows the $4 \mathrm{~mm} \mathrm{~d}^{-1}$ contour of the IGCM4 control integration (as in h). (a,b) $\alpha=-0.5$, (c,d) $\alpha=0,(\mathrm{e}, \mathrm{f}) \alpha=0.5$, (g,h) $\alpha=1$, control integration, $(\mathrm{i}, \mathrm{j}) \alpha=1.5,(\mathrm{k}, \mathrm{l}) \alpha=2$. 


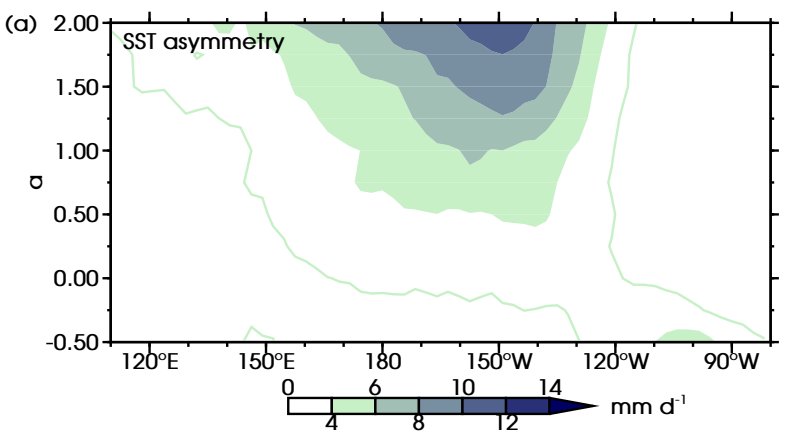

(b)

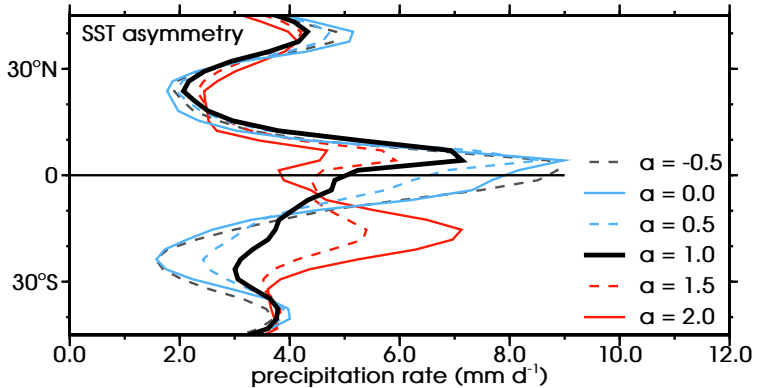

Fig. 3 SST asymmetry experiments. (a) Time mean precipitation rate (November to April) between $15^{\circ}-25^{\circ} \mathrm{S}$ (shaded colours, $\mathrm{mm} \mathrm{d}^{-1}$ ). The green line shows the $2 \mathrm{~mm} \mathrm{~d}^{-1}$ contour. (b) November to April time-mean longitude-mean $\left(150^{\circ} \mathrm{E}-90^{\circ} \mathrm{W}\right)$ precipitation rate $(\mathrm{mm}$ $\left.\mathrm{d}^{-1}\right)$. Grey dashed line $\alpha=-0.5$, blue solid line $\alpha=0$, blue dashed line $\alpha=0.5$, black solid line $\alpha=1$, control integration, red dashed line $\alpha=1.5$, red solid line $\alpha=2$. 

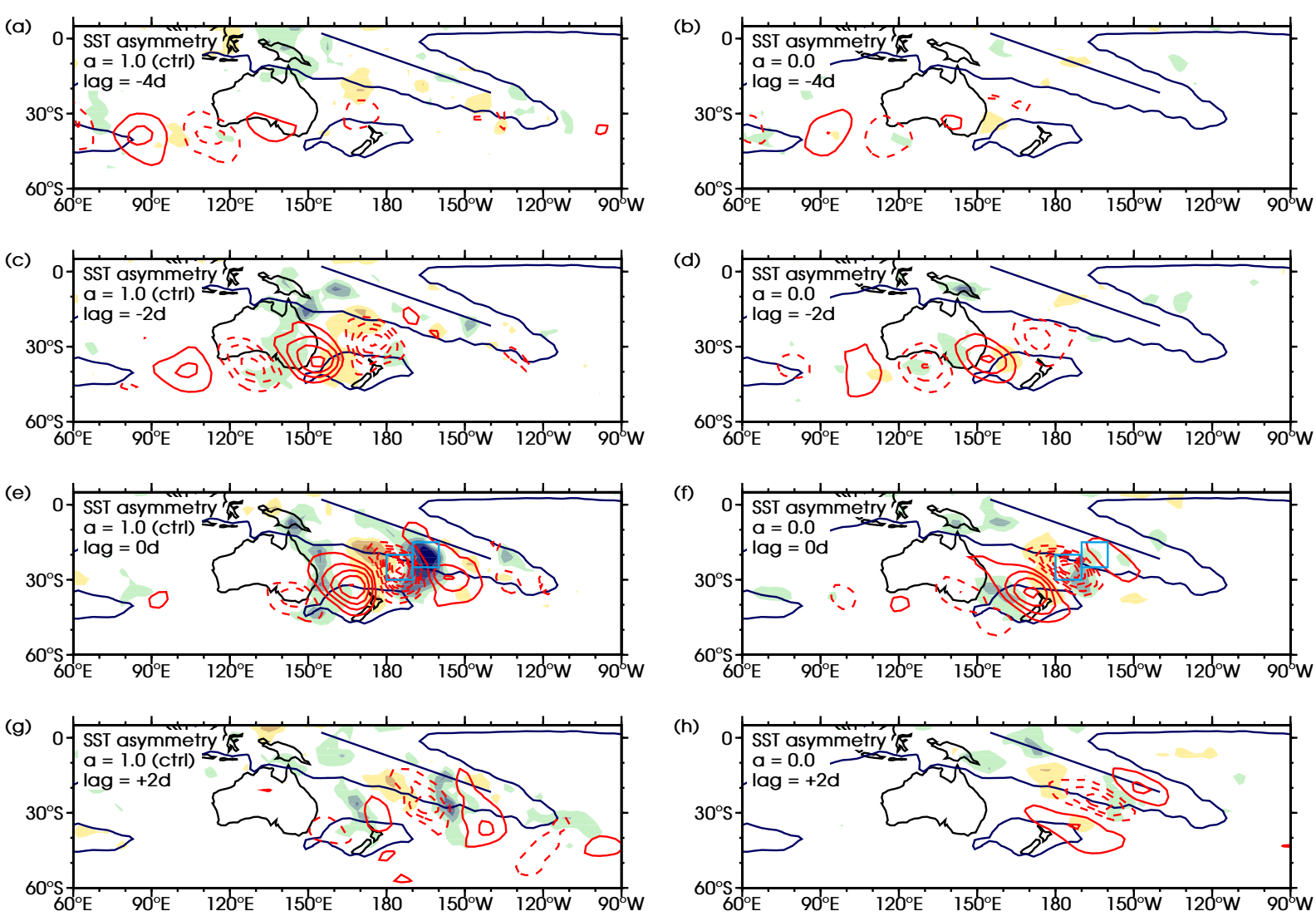

(i)
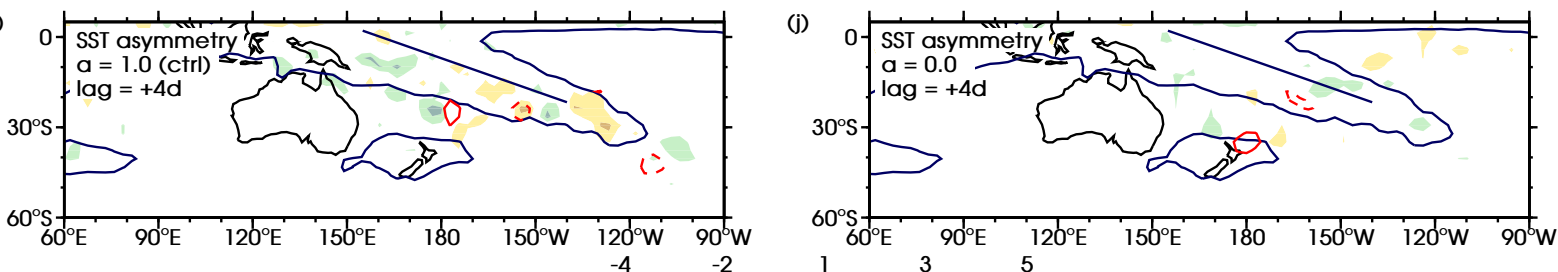

Fig. 4 SST asymmetry experiments. Lagged composites of anomalies of 200 hPa vorticity (contours, interval $7.5 \times 10^{-6} \mathrm{~s}^{-1}$, negative contours dashed, zero contour omitted) and precipitation rate (shaded colours, $\mathrm{mm} \mathrm{d}^{-1}$ ). Dark blue lines show the SPCZ axis and the $4 \mathrm{~mm} \mathrm{~d}^{-1}$ contour in the control integration (as in Fig. 1b), light blue boxes in (e,f) are areas for the vorticity time series and vertical profiles (see text). (a,c,e,g,i) $\alpha=1$, control integration, $(\mathrm{b}, \mathrm{d}, \mathrm{f}, \mathrm{h}, \mathrm{j}) \alpha=0$. Lags: $(\mathrm{a}, \mathrm{b})$ event -4 days, $(\mathrm{c}, \mathrm{d})$ event -2 days, (e,f) event, $(\mathrm{g}, \mathrm{h})$ event +2 days, $(\mathrm{i}, \mathrm{j})$ event +4 days. 

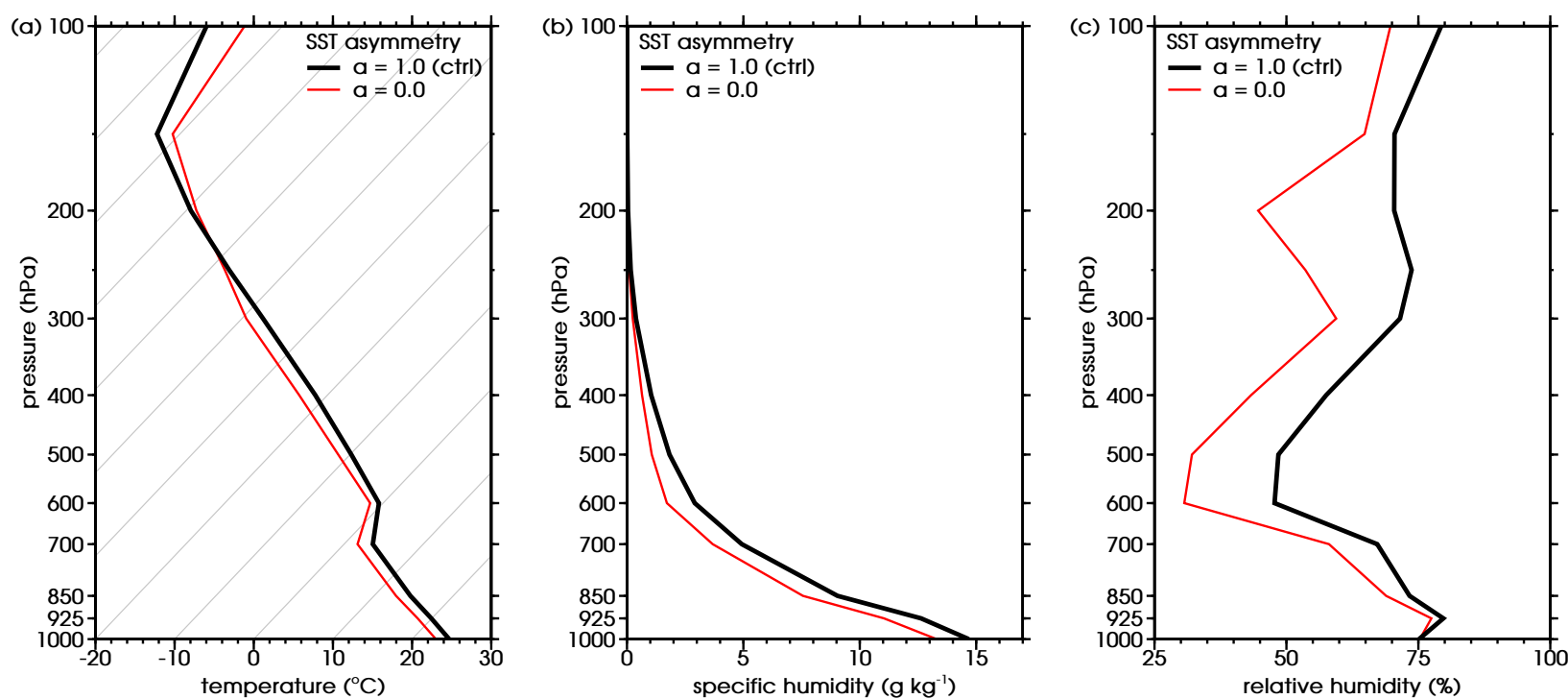

Fig. 5 SST asymmetry experiments. Vertical profiles of (a) temperature $\left({ }^{\circ} \mathrm{C}\right)$, (b) specific humidity $\left(\mathrm{g} \mathrm{kg}^{-1}\right)$ and (c) relative humidity (\%) in the northeastern blue box (see Figs. 4e, 4f) in the composites (event, no lag). Temperature is plotted on a Skew T-log P diagram, skew grey lines are isotherms. $\alpha=1$, control integration, black line and $\alpha=0$ red line.

(a) 30

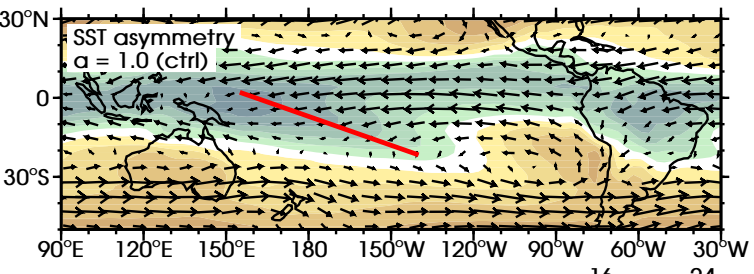

(b) $30^{\circ} \mathrm{N}$ SST asymmetry $\frac{1}{2}$,

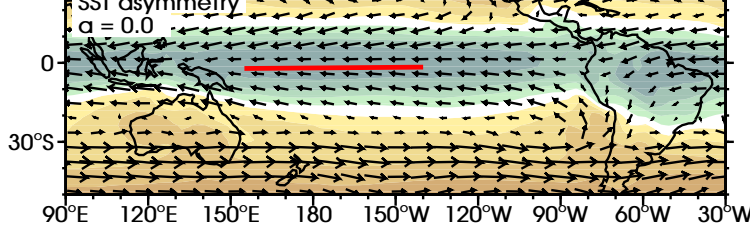

$90^{\circ} \mathrm{E} \quad 120^{\circ} \mathrm{E} \quad 150^{\circ} \mathrm{E} \quad 180 \quad 150^{\circ} \mathrm{W} 120^{\circ} \mathrm{W} \quad 90^{6} \mathrm{~W} \quad 60^{\circ} \mathrm{W} \quad 30^{\circ} \mathrm{W}$

$\overrightarrow{10} \mathrm{~m} \mathrm{~s}^{-1}$

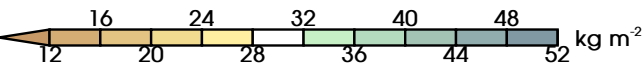

(c) 30

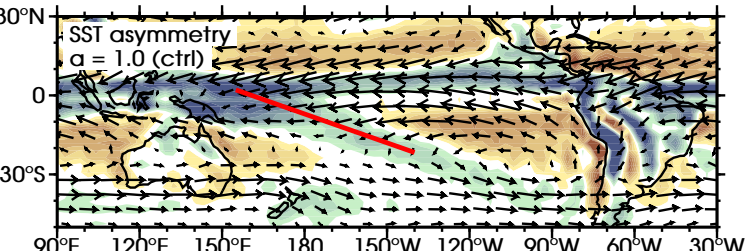

(d) $30^{\circ} \mathrm{N}$ SST asymmetry

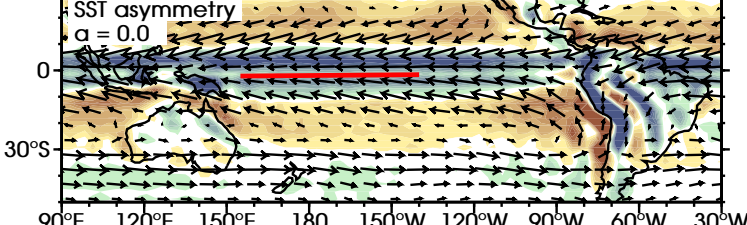

$\overrightarrow{250} \mathrm{~kg} \mathrm{~s}^{-1} \mathrm{~m}^{-1}$

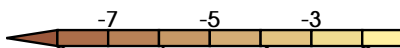

Fig. 6 SST asymmetry experiments. (Top) time mean column integrated specific humidity (November to April, shaded colours, $\mathrm{kg} \mathrm{m}^{-2}$ ) and $1000-600 \mathrm{hPa}$ mean wind (vectors, $\mathrm{m}$ $\mathrm{s}^{-1}$, reference vector bottom left). (Bottom) the corresponding column integrated moisture transport (vectors, $\mathrm{kg} \mathrm{s}^{-1} \mathrm{~m}^{-1}$, reference vector bottom left) and moisture convergence (shaded colours, $\mathrm{kg} \mathrm{d}^{-1} \mathrm{~m}^{-2}$ ). The thick diagonal red lines show the computed SPCZ axis location. (a,c) $\alpha=1$, control integration, (b,d) $\alpha=0$. 
(a) $30^{\circ}$

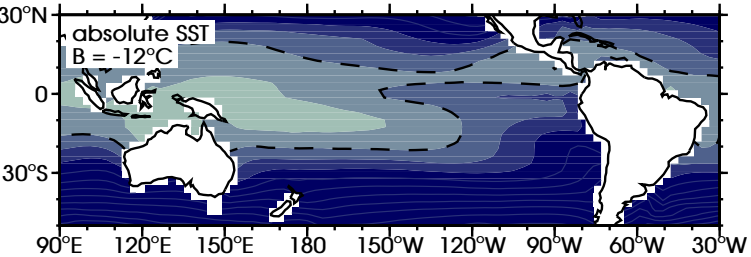

(c) 30

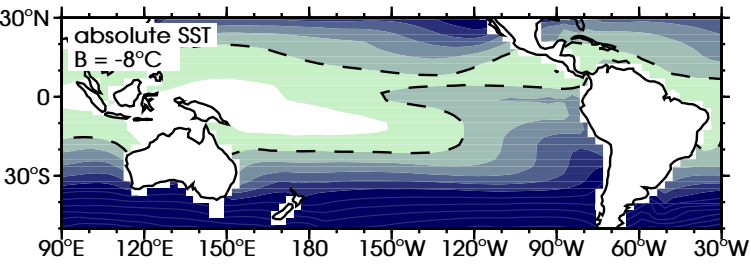

(e) $30^{\circ}$

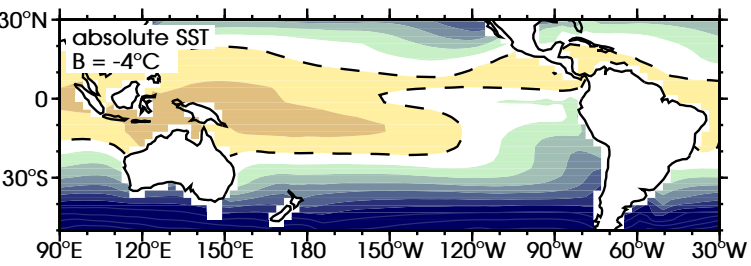

(g) $30 \%$

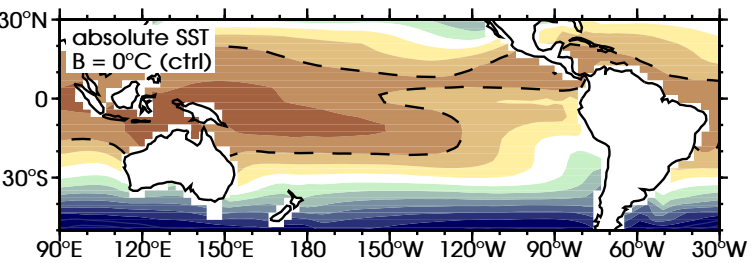

(i)

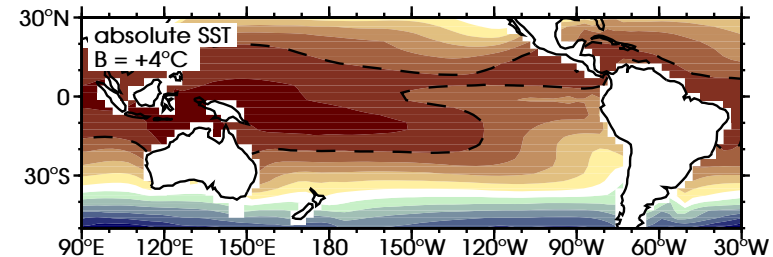

(k) $30^{\circ} \mathrm{N} \underset{\text { absolute SST }}{, \frac{1}{,}}$

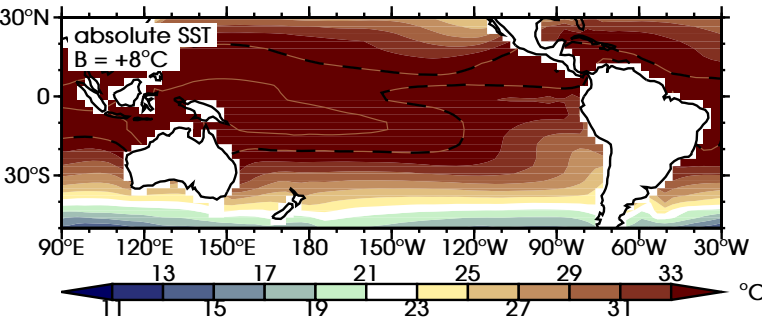

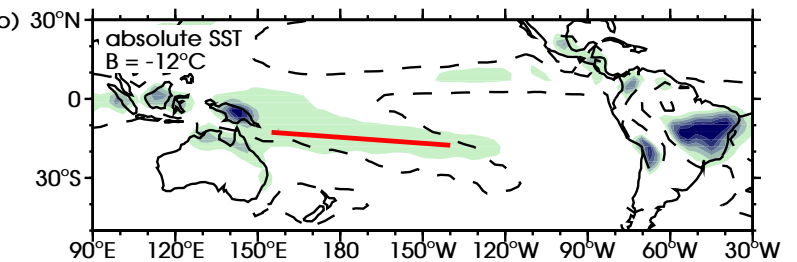

(d) $30^{\circ} \mathrm{N} \frac{1}{\text { absolute SST }}$

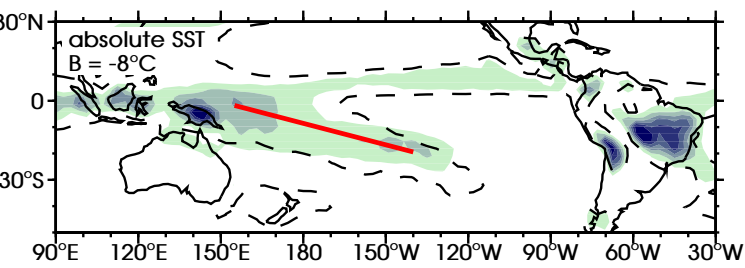

(f)

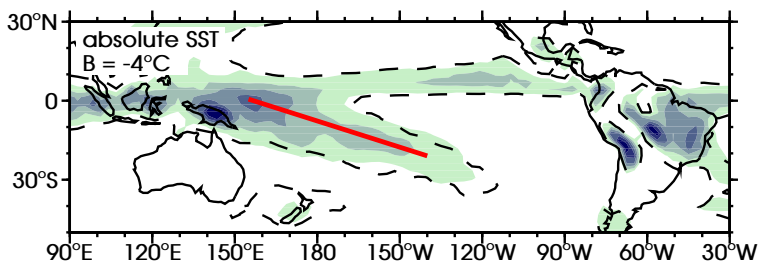

(h) $30^{\circ}$

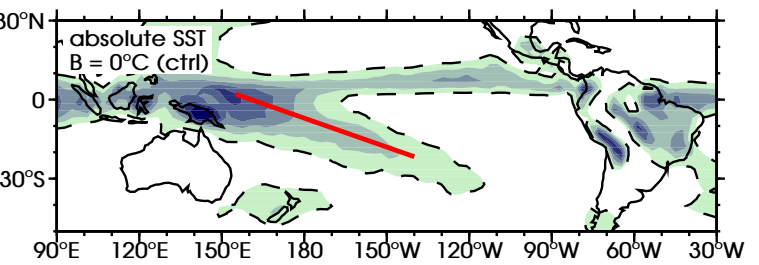

(j)

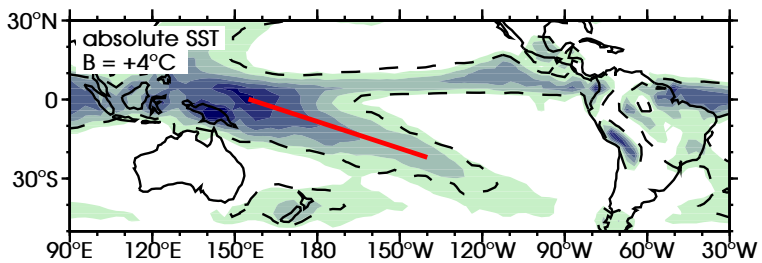

(I)

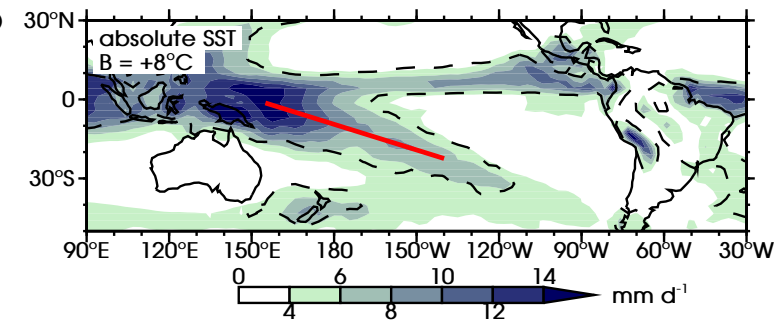

Fig. 7 Absolute SST experiments. (Left) Time mean SST forcing (November to April, shaded colours, ${ }^{\circ} \mathrm{C}$ ), black dashed line shows the $27^{\circ} \mathrm{C}$ contour of the IGCM4 control integration (as in g), brown line contours show SST contours for $35^{\circ} \mathrm{C}$ and warmer $\left(+2^{\circ} \mathrm{C}\right.$ contour interval), blue line contours show SST contours for $9^{\circ} \mathrm{C}$ and colder $\left(-2^{\circ} \mathrm{C}\right.$ contour interval). (Right) The corresponding time mean precipitation rate (shaded colours, $\mathrm{mm}$ $\mathrm{d}^{-1}$ ). The thick diagonal red line shows the computed SPCZ axis location, the black dashed line in shows the $4 \mathrm{~mm} \mathrm{~d}^{-1}$ contour of the IGCM4 control integration (as in $\mathrm{h}$ ). $(\mathrm{a}, \mathrm{b})$ $\beta=-12^{\circ} \mathrm{C}$, (c,d) $\beta=-8^{\circ} \mathrm{C},(\mathrm{e}, \mathrm{f}) \beta=-4^{\circ} \mathrm{C},(\mathrm{g}, \mathrm{h}) \beta=0^{\circ} \mathrm{C}$, control integration, (i,j) $\beta=+4^{\circ} \mathrm{C}$, $(\mathrm{k}, \mathrm{l}) \beta=+8^{\circ} \mathrm{C}$. 

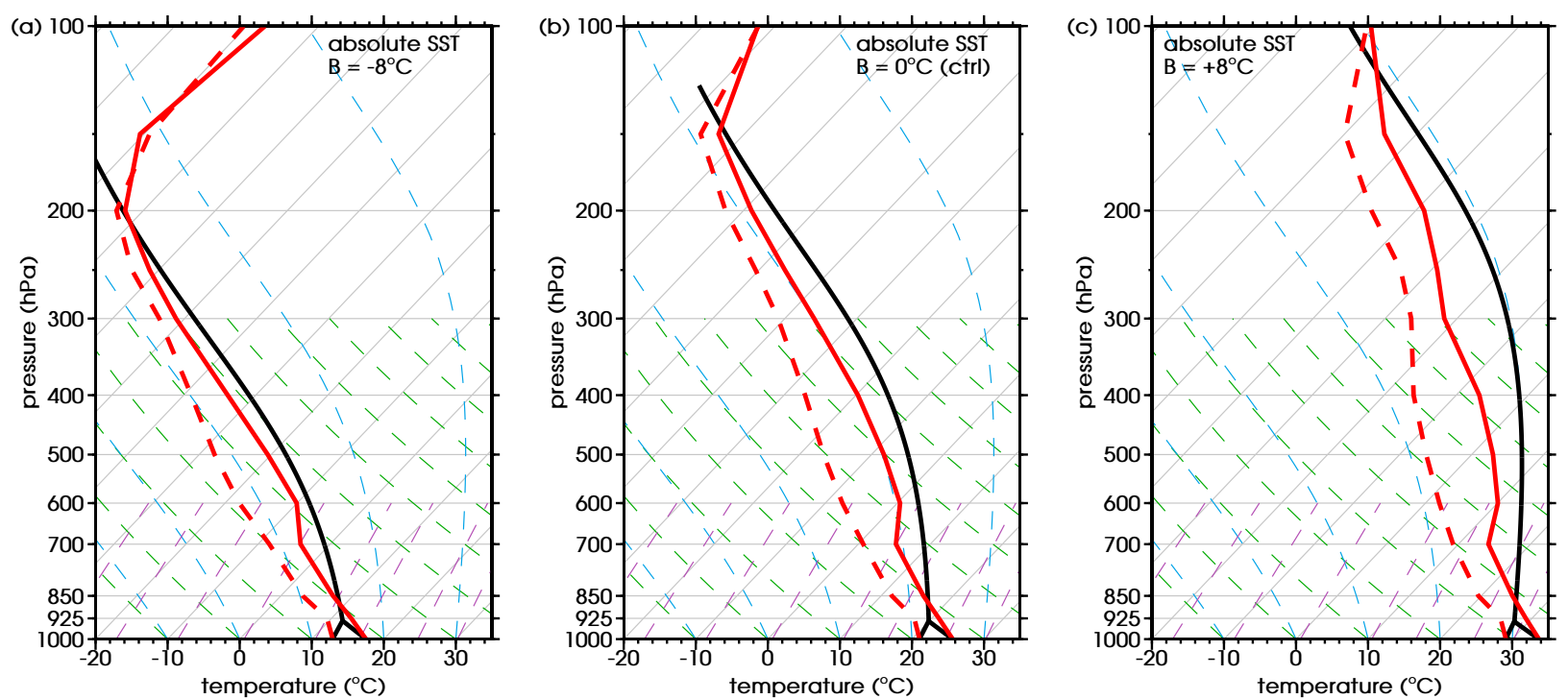

Fig. 8 Absolute SST experiments. Time mean vertical profiles of temperature (November to April, ${ }^{\circ} \mathrm{C}$, solid red line) and dewpoint temperature $\left({ }^{\circ} \mathrm{C}\right.$, dashed red line) along the computed SPCZ axis plotted on a Skew T-log P diagram. An idealised lifted air parcel is shown as a black line. Horizontal grey lines are isobars, skew grey lines are isotherms, green dashed lines are dry adiabats, blue dashed lines are saturated adiabats, purple dashed lines are isopleths of saturation mixing ratio. (a) $\beta=-8^{\circ} \mathrm{C}$, (b) $\beta=0^{\circ} \mathrm{C}$, control integration, (c) $\beta=+8^{\circ} \mathrm{C}$ 


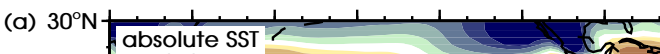

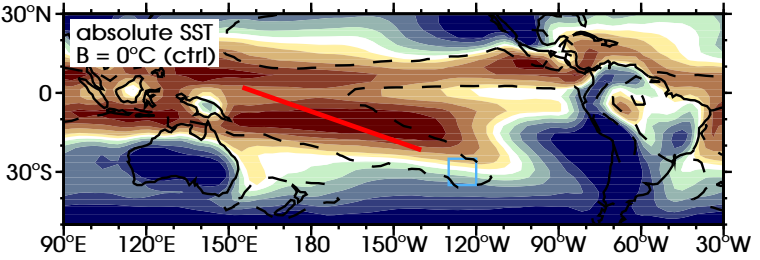

(b) $30^{\circ} \mathrm{N} \frac{1}{\sqrt{\text { absolute SST }}}$

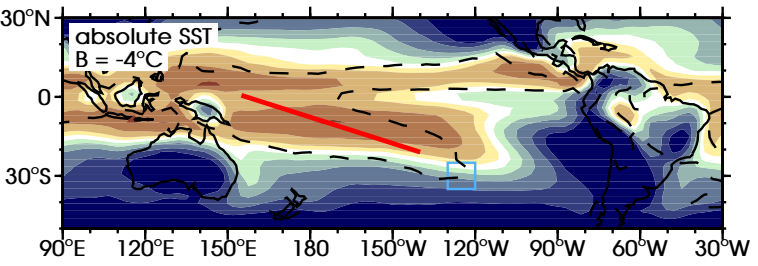

(c) 30
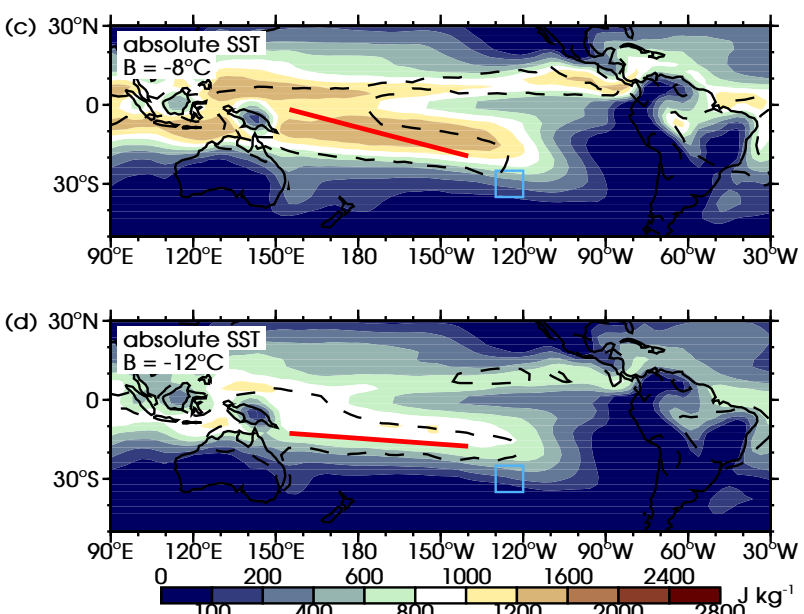

Fig. 9 Absolute SST experiments. Time mean CAPE (November to April, shaded colours, $\left.\mathrm{J} \mathrm{kg}^{-1}\right)$. The thick diagonal red lines show the computed SPCZ axis location, the black dashed line in shows the $4 \mathrm{~mm} \mathrm{~d}^{-1}$ precipitation contour (as in Fig. 7), the light blue boxes are the area for the computation of the mean CAPE value (see text). (a) $\beta=0^{\circ} \mathrm{C}$, control integration, (b) $\beta=-4^{\circ} \mathrm{C}$, (c) $\beta=-8^{\circ} \mathrm{C}$, (d) $\beta=-12^{\circ} \mathrm{C}$. 

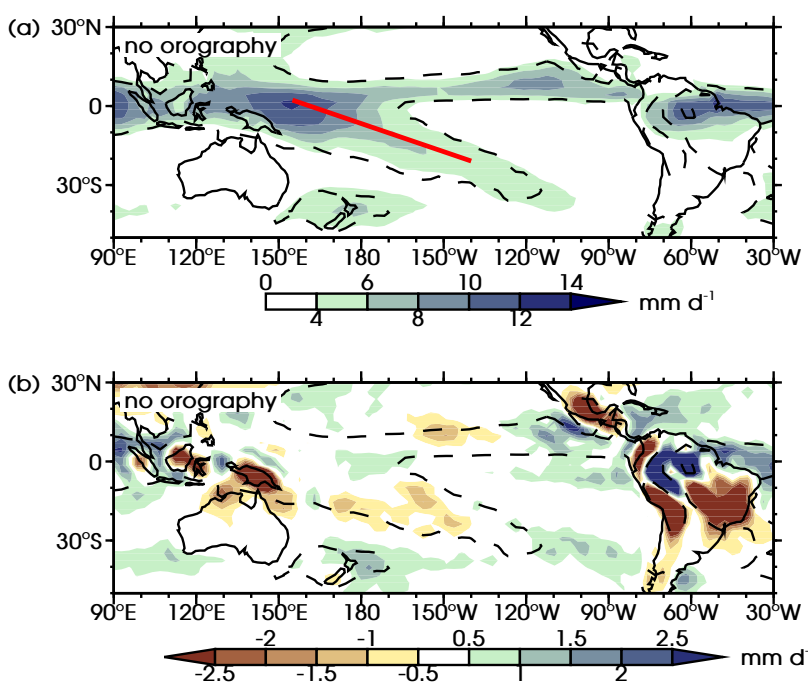

Fig. 10 No-orography experiment. (a) Time mean precipitation rate (November to April, shaded colours, $\mathrm{mm} \mathrm{d}^{-1}$ ) and (b) difference with the IGCM4 control integration (experiment minus control, shaded colours, $\mathrm{mm} \mathrm{d}^{-1}$ ). The thick diagonal red line in (a) shows the computed SPCZ axis location, the black dashed line in $(\mathrm{a}, \mathrm{b})$ shows the $4 \mathrm{~mm} \mathrm{~d}^{-1}$ contour of the IGCM4 control integration (as in Fig. 1b). 
(a) 30

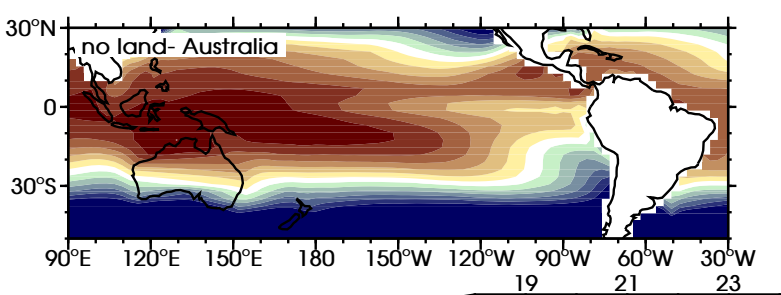

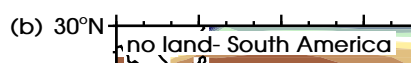

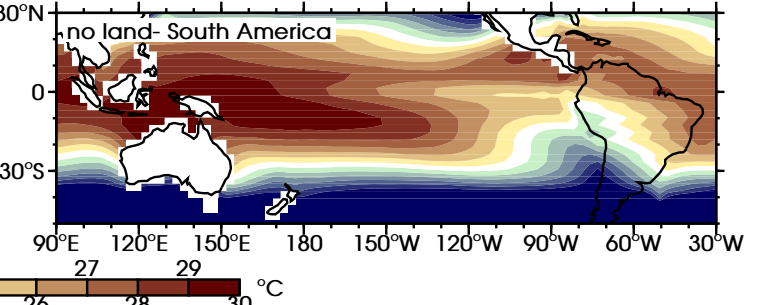

(c) $30^{\circ} \mathrm{N}+\frac{1}{\text { no land- Australia }}$

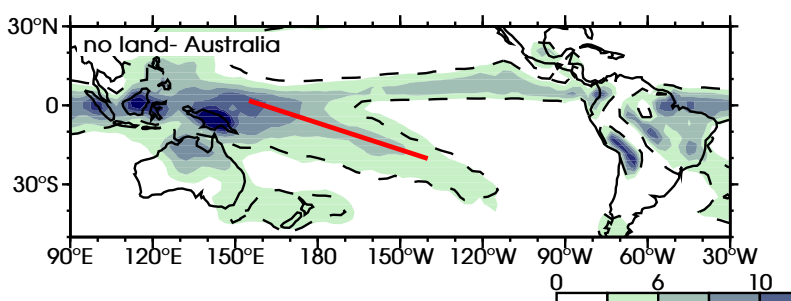

(d) $30^{\circ} \mathrm{N}$ no land- South America

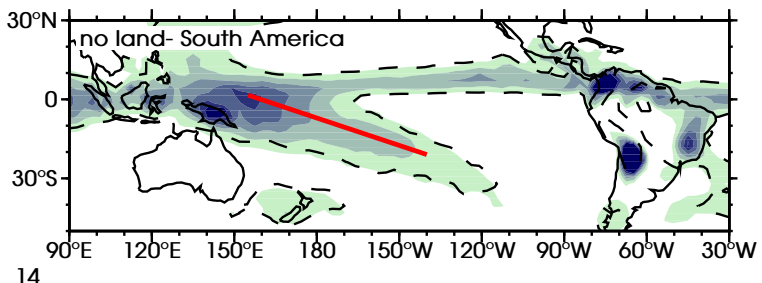

(e)

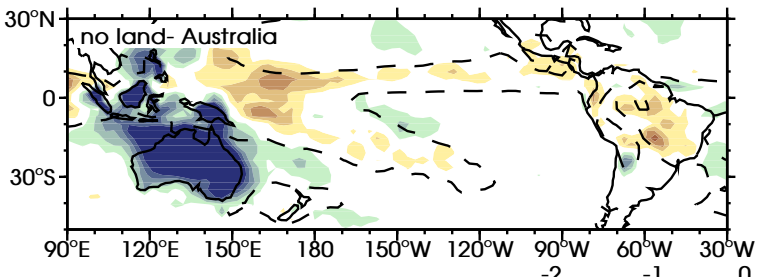

(f) 30

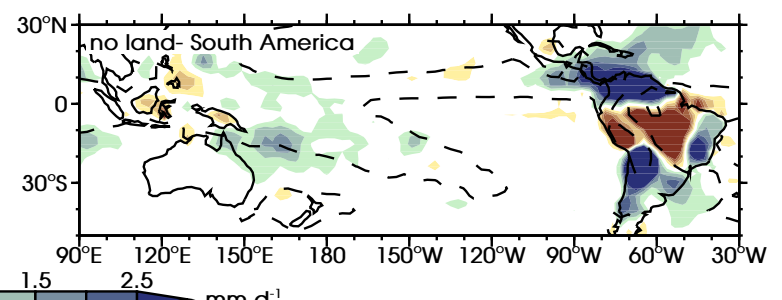

Fig. 11 No-land experiment. (a,b) Time mean SST forcing (November to April, shaded colours, $\left.{ }^{\circ} \mathrm{C}\right),(\mathrm{c}, \mathrm{d})$ precipitation rate (shaded colours, $\mathrm{mm} \mathrm{d}^{-1}$ ) and $(\mathrm{e}, \mathrm{f})$ precipitation rate difference with the IGCM4 control integration (experiment minus control, shaded colours, $\left.\mathrm{mm} \mathrm{d}^{-1}\right)$. The thick diagonal red line in (c,d) shows the computed SPCZ axis location, the black dashed line in (c,d,e,f) shows the $4 \mathrm{~mm} \mathrm{~d}^{-1}$ contour of the IGCM4 control integration (as in Fig. 1b). (a,c,e) no Australia and (b,d,f) no South America. 


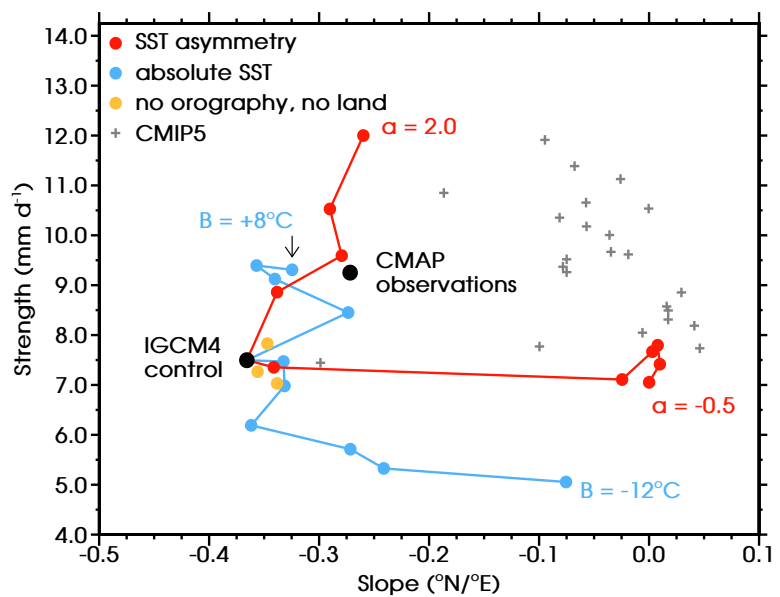

Fig. 12 Time mean SPCZ strength (November to April, $\mathrm{mm} \mathrm{d}^{-1}$ ) plotted against SPCZ slope $\left({ }^{\circ} \mathrm{N} /{ }^{\circ} \mathrm{E}\right)$. Black dots are the CMAP observations and the IGCM4 control integration. Experiments: no orography and no land (orange), SST asymmetry (red), absolute SST (blue), CMIP5 historical experiments (grey). 
(a) Normal conditions

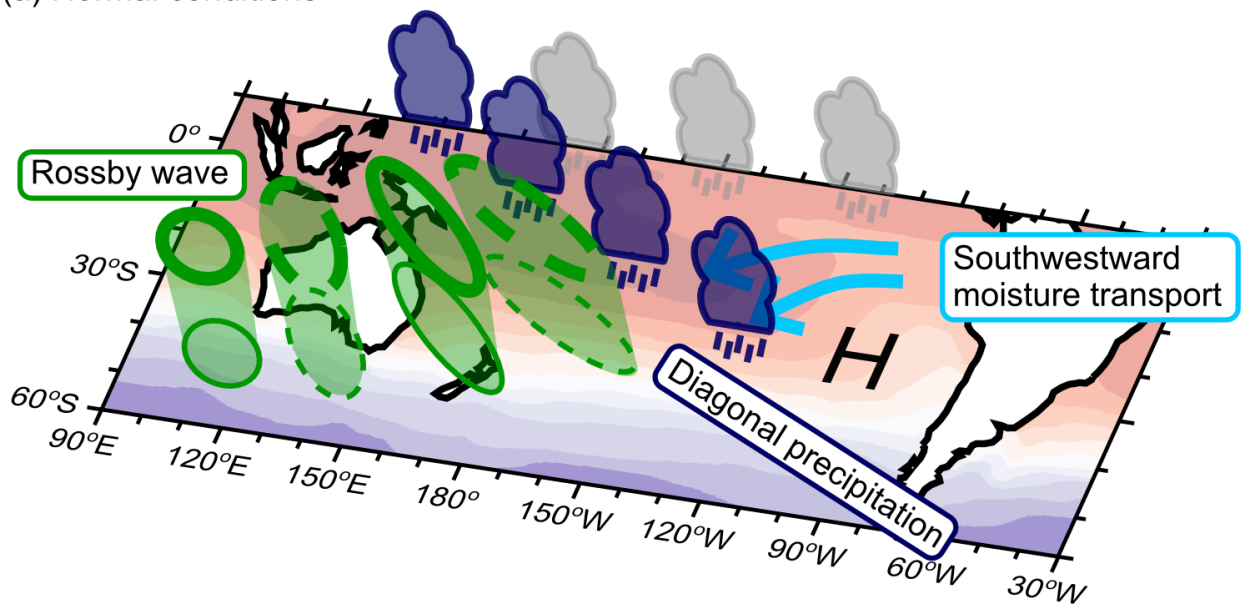

(b) Zonally symmetric conditions

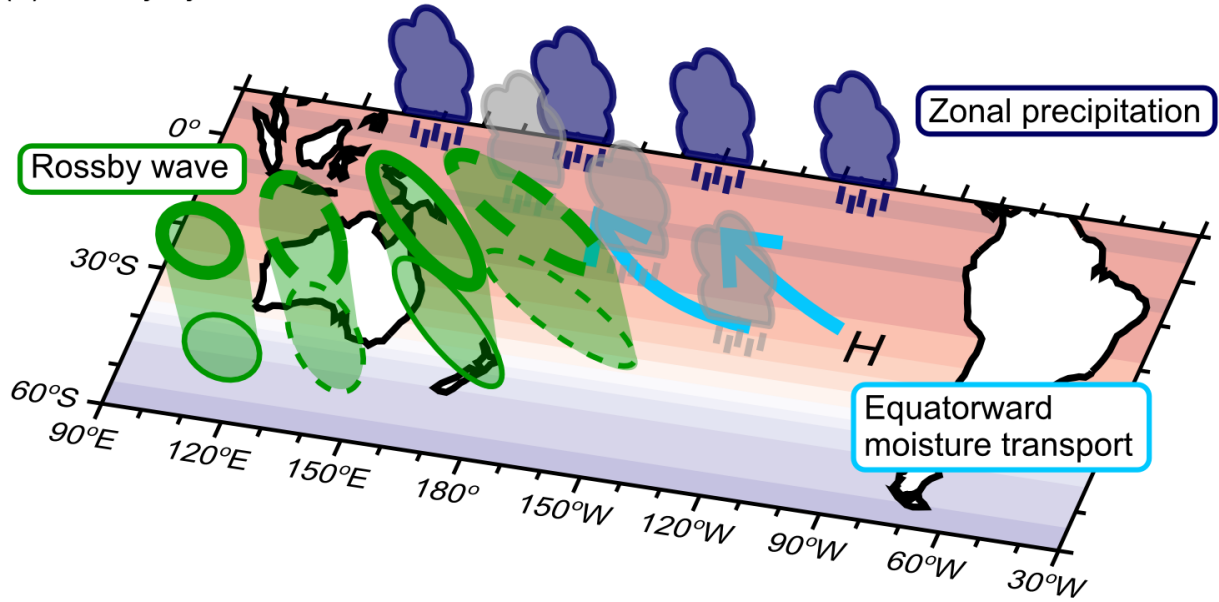

Fig. 13 (a) Schematic of the conditions and mechanism of a diagonal SPCZ. An asymmetrical SST distribution generates a subtropical anticyclone over the southeast Pacific, on its western flank this area transports moisture southwestward into the SPCZ region. Dynamical forcing from equatorward propagating Rossby waves then triggers convection in a northwest-southeast oriented band, parallel to an area of reduced static stability ahead of a cyclonic vorticity anomaly. (b) As (a) but for zonally symmetric SST conditions. The subtropical anticyclone weakens and moisture transport is equatorward. Despite similar diagonally oriented dynamical forcing, precipitation forms in a zonal band along the equator. 